University of Louisville

ThinkIR: The University of Louisville's Institutional Repository

Electronic Theses and Dissertations

$1-2018$

\title{
Optimization of PLGA and PLGA-dasatinib particles through a Taguchi design approach
}

Rayeanne N Balgemann

University of Louisville

Follow this and additional works at: https://ir.library.louisville.edu/etd

Part of the Biomedical Engineering and Bioengineering Commons

\section{Recommended Citation}

Balgemann, Rayeanne N, "Optimization of PLGA and PLGA-dasatinib particles through a Taguchi design approach" (2018). Electronic Theses and Dissertations. Paper 3455.

https://doi.org/10.18297/etd/3455

This Master's Thesis is brought to you for free and open access by ThinkIR: The University of Louisville's Institutional Repository. It has been accepted for inclusion in Electronic Theses and Dissertations by an authorized administrator of ThinkIR: The University of Louisville's Institutional Repository. This title appears here courtesy of the author, who has retained all other copyrights. For more information, please contact thinkir@louisville.edu. 


\title{
OPTIMIZATION OF PLGA AND PLGA-DASATINIB PARTICLES THROUGH A TAGUCHI DESIGN APPROACH
}

\author{
By \\ Rayeanne Balgemann \\ B.S, University of Louisville, December 2016

\begin{abstract}
A Thesis
Submitted to the Faculty of the

University of Louisville

J.B. Speed School of Engineering

as Partial Fulfillment of the Requirements

for the Professional Degree
\end{abstract}

\section{MASTERS OF ENGINEERING}

Department of Bioengineering

December 2018 
OPTIMIZATION OF PLGA AND PLGA DASATINIB PARTICLES THROUGH A TAGUCHI DESIGN APPROACH

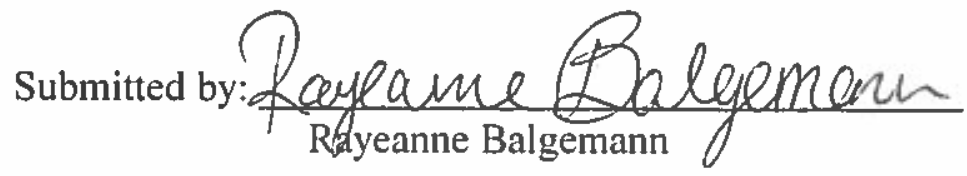

A Thesis Approved On

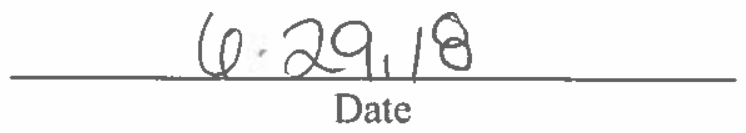

by the following Reading and Examination Committee
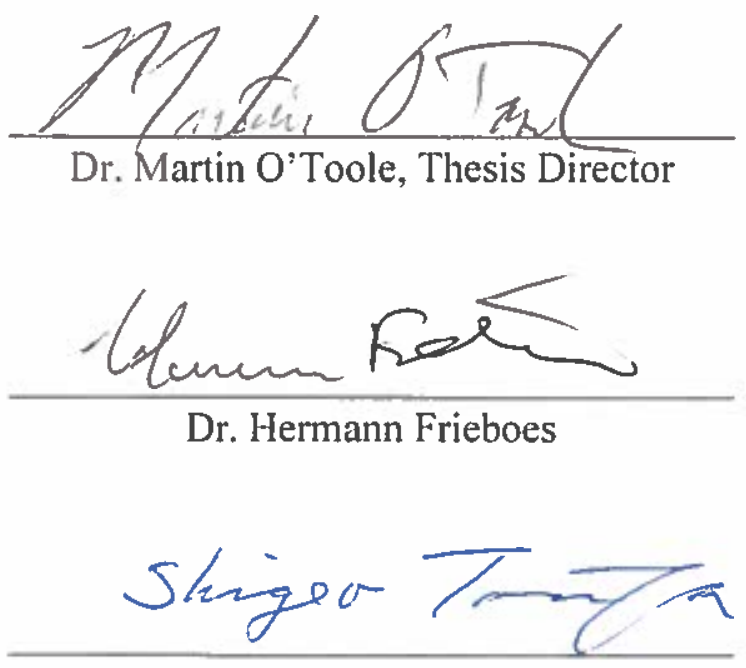

Dr. Shigeo Tamiya

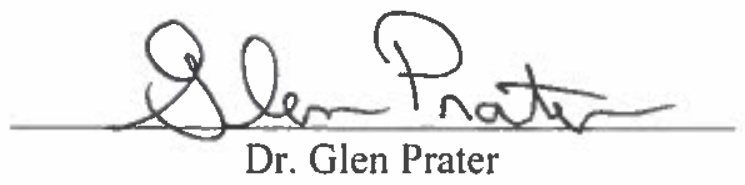

ii 


\section{ACKNOWLEDGEMENTS:}

Thank you to my thesis director Dr. Martin O'Toole for his guidance, support, and mentorship throughout the project. Thank you to the members of my thesis committee Dr. Shigeo Tamiya, Dr. Hermann Frieboes, Dr. Glen Prater and the chair of the Bioengineering department Dr. Ayman El-Baz. Additional thanks to our lab manager Betty Nunn for her support, mentorship, guidance, and helpfulness throughout the project. Thank you to Dr. Rajat Chauhan for taking the time to teach me, mentor me, answer countless questions, and for always being both supportive and available. Thank you to the current O'Toole lab members who made the lab an inviting environment and were always there to lend a hand or answer a question when I needed help: Kurtis James and Emtias Chowdhury. Thank you to the University of Louisville Bioengineering Department for a great 5 years and a wonderful educational experience. Finally thank you to my family and friends for the continued patience and support during this journey. 


\begin{abstract}
$\underline{\text { ABSTRACT }}$
Proliferative vitreoretinopathy (PVR) is a disease of the retina in the human eye. Retinal pigment epithelium cells (RPE) undergo an epithelial to mesenchymal transition in response to retinal trauma. This transition gives the cells mobility and allows them to potentially infiltrate the vitreous chamber and deposit on either side of the retina. Once cell deposition has occurred, along with several other transformed cells derived from cell types such as Müller glia, these migratory cells can form a membrane contiguous with the retinal extracellular matrix and, upon contraction, cause wrinkling of the retina. If left untreated PVR can lead to traction retinal detachment and blindness.
\end{abstract}

There are limitations to the methods currently being used to treat this disease. The most common treatment option for PVR is surgery, which has a limited success rate. Pharmacological agents, such as the protein kinase inhibitor dasatinib, are also being investigated for their efficacy in treating this condition. Dasatinib has been shown to prevent PVR and associated cellular functions in porcine animal models in a dosedependent manner. One of the limitations of using dasatinib, however, is the need for recurring drug injections to keep a therapeutic level in the eye and prevent retinal contracture.

Targeted ocular drug delivery, through the use of polymeric nanoparticles, offers a promising method to deliver dasatinib to the eye without the need for frequent daily injections. In this project, spray drying, a technique that produces drug-encapsulated polymer shells from a liquid dispersion, was used to encapsulate dasatinib in PLGA 
particles. Particle size was optimized to produce particles under $1 \mu \mathrm{m}$ in diameter through the use of a Taguchi statistical design approach. Particles were manufactured on a Büchi B-90 nanospray spray dryer. PLGA particle optimization was completed before the production of PLGA dasatinib particles. After PLGA particle optimization, PLGAdasatinib particles were produced $(n=3)$ and their size analyzed using scanning electron microscopy. The release kinetics of dasatinib from the PLGA particles was analyzed using UV-Visible spectroscopy from this the drug release kinetics and mechanism was determined. 


\section{TABLE OF CONTENTS}

SIGNATURE PAGE

ACKNOWLEDGMENTS

ABSTRACT

NOMENCLATURE vi

LIST OF TABLES vii

LIST OF FIGURES viii

I. INTRODUCTION 1

a. Anatomy of the eye 1

b. Proliferative vitreoretinopathy 5

c. Current treatments and limitations $\quad 7$

d. Dasatinib and proliferative vitreoretinopathy 9

$\begin{array}{lr}\text { e. Ocular drug delivery } & 10\end{array}$

$\begin{array}{ll}\text { f. Controlled drug release } & 12\end{array}$

g. Spray drying manufacturing method 15

h. Instrumentation and equipment 17

i. Taguchi matrix and Taguchi design $\quad 19$

$\begin{array}{ll}\text { II. PROCEDURE } & 20\end{array}$

a. Chemical supplies 20

b. Synthesis of PLGA and PLGA dasatinib solution 20

c. Spray drying of PLGA based on Taguchi design 22

d. Spray drying of PLGA based on best Taguchi design 22

e. Spray drying of PLGA dasatinib particles 22

$\begin{array}{ll}\text { f. Particle characterization } & 23\end{array}$

g. Statistical analysis of particle size and morphology 24

h. Dasatinib release studies 25

III. RESULTS AND DISCUSSION 26

a. Prior PLGA dasatinib particles 26

b. PLGA and PLGA-D optimization 27

IV. CONCLUSIONS AND RECOMMENDATIONS 35

REFRENCES CITED 36

$\begin{array}{ll}\text { APPENDIX I } & 37\end{array}$

$\begin{array}{ll}\text { VITA } & 39\end{array}$ 


\section{NOMENCLATURE}

PLGA: poly-lactic-co-glycolic acid

PBS: $\quad$ phosphate buffered saline

PVR: $\quad$ proliferative vitreoretinopathy

RPE: retinal pigment epithelium

EMT: epithelial mesenchymal transition

ECM: $\quad$ extracellular matrix

PDGF: $\quad$ platelet derived growth factor

PDGFR: $\quad$ platelet derived growth factor receptor

DCM: dichloromethane

(w/v \%): $\quad$ percent weight by volume

$\mu \mathrm{m}: \quad$ micrometer

$\mu \mathrm{M}: \quad$ micromolar

C: $\quad$ degrees Celsius

L/min: $\quad$ liters per minute

BSA: bovine serum albumin

PLGA-D: PLGA dasatinib particles

PPV: $\quad$ pars plana vitrectomy

SEM: $\quad$ scanning electron microscopy

EHT: electron high tension 


\section{LIST OF TABLES}

Page

TABLE I. Parameters for spray drying PLGA particles 21

TABLE II. Taguchi matrix design runs and levels 22

TABLE III. PLGA particle $\mathrm{S} / \mathrm{N}$ ratio, size, and axial ratio 28

TABLE IV. Parameter level effect on particle size 29

TABLE V. Parameter level effect on particle axial ratio 29

TABLE VI. Varying PLGA w/v\% effect on particle size and axial ratio 30

TABLE VII. Effect of levels on PLGA-D particle size and axial ratio 31

TABLE VIII. Zeta potential of submicrometer particles 33 


\section{LIST OF FIGURES}

Page

Figure 1. Anatomy of the human eye 1

Figure 2. Anatomy of the human retina 2

Figure 3. Anatomy of the human retina with neuronal layers 3

$\begin{array}{ll}\text { Figure 4. Routes of ocular drug delivery } & 10\end{array}$

Figure 5. Büchi B-90 nano spray dryer 17

Figure 6. Zeiss Supra 35 SEM microscope 23

$\begin{array}{ll}\text { Figure 7. Plasma coater } & 23\end{array}$

Figure 8. Dasatanib UV-Vis calibration curve 26

Figure 9. PLGA particle size distribution 27

Figure 10. SEM of PLGA-D T1 31

Figure 11. SEM of PLGA-D T2 31

Figure 12. SEM of PLGA D T3 31

Figure 13. Submicrometer particle controlled release 33

Figure 14. Submicrometer particle controlled release kinetics 34 


\section{INTRODUCTION}

\section{A. Anatomy of the Eye:}

To understand the disease process of proliferative vitreoretinopathy it is useful to first understand the basic anatomy of the human eye. The shape of the human eye is an oblate spheroid that has three primary layers: the fibrous coat, vascular coat, and nervous coat. ${ }^{1}$ A basic schematic of the anatomy of the eye can be seen in Figure 1. The outermost layer of the eye is the cornea which acts as a transparent meniscus lens that aids in focusing light on the retina. ${ }^{2,3}$ The cornea is the anterior $1 / 6$ of the fibrous coat which comes in contact with the environment. The remaining $5 / 6$ of the fibrous coat of the eye is made up of the sclera, which is commonly referred to as the whites of the eye. The sclera of the eye helps maintain ocular shape and protect the eye from trauma. ${ }^{4}$ The meeting point between the cornea and the sclera is known as the limbus.

\section{Anatomy of the Eye}

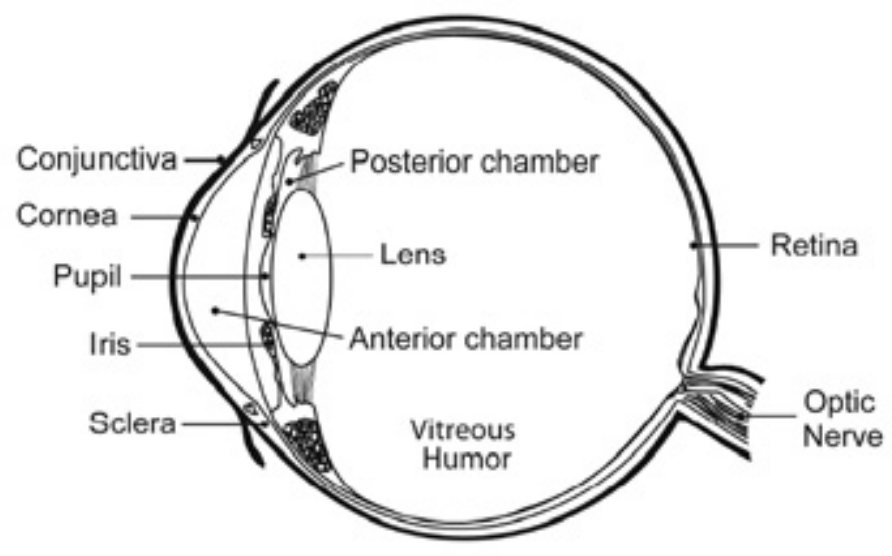

FIGURE 1. Anatomy of the human eye $\mathrm{s}^{5}$ 
The vascular coat of the eye serves to nourish the eye and is made up of the iris, ciliary body, and choroid. The iris acts as a control point for the amount of light reaching the retina through dilation and constriction of the pupil. ${ }^{2}$ The lens of the eye is posterior to the iris. The space between the iris and the lens of the eye is known as the posterior chamber. The ciliary body of the eye controls the lens as well as aqueous humor production. ${ }^{6}$ The choroid is the main vascular tissue of the eye and provides nourishment to the organ.

The nervous coat of the eye is composed of the retina, which is the part of the eye that is responsible for vision. The retina is the innermost layer of the eye and contains specialized cells called rods and cones that help the eye process light through the conversion of the electromagnetic waves into neural impulses processed by the brain, Figure $2 .^{4}$

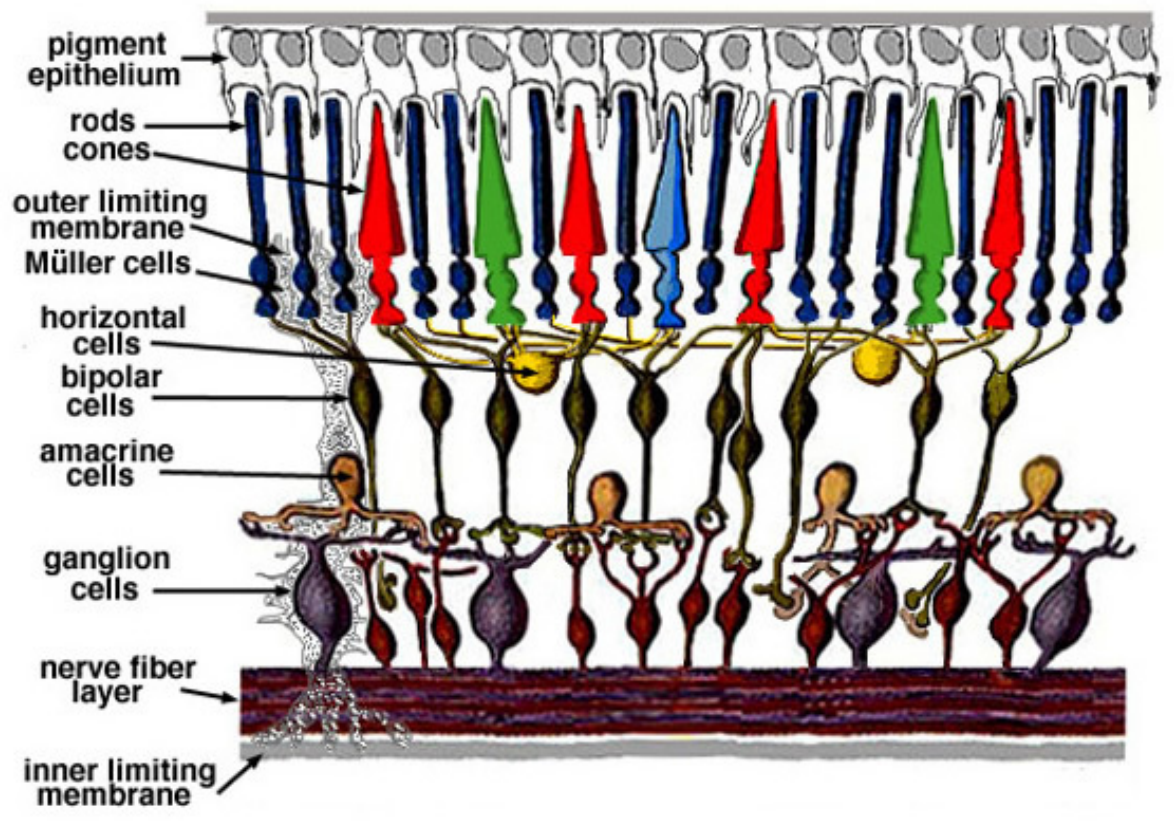

FIGURE 2. Anatomy of the human retina 
The retina lines the posterior portion of the eye and is around $0.5 \mathrm{~mm}$ in thickness. ${ }^{7}$ It communicates with the brain through the optic nerve which inserts into the retina producing the optic disc, the blind spot in human vision. The human retina has three layers of nerve cells and two layers of neuronal synapses, Figure 3.

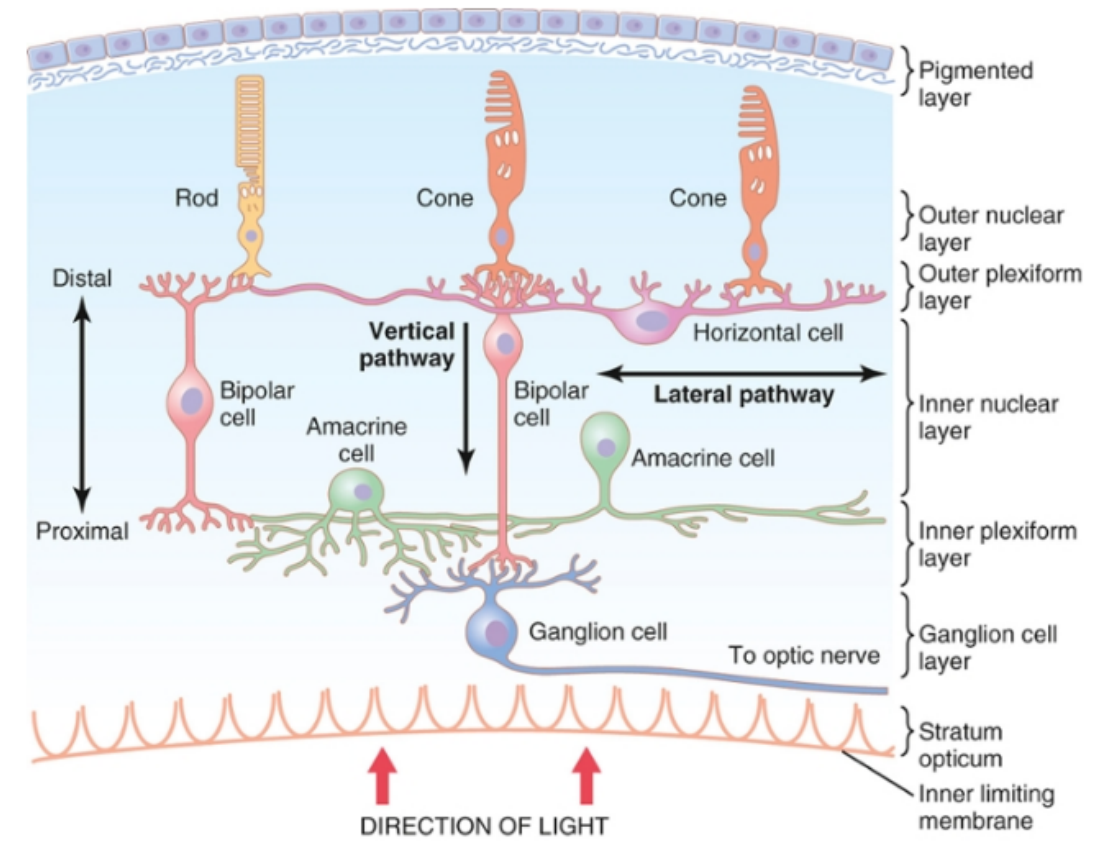

FIGURE 3. Anatomy of the human retina with neuronal layers ${ }^{8}$

The cells that line the most posterior portion of the retina are the retina pigmented epithelium cells (RPE), which are a main contributor in the disease of proliferative vitreoretinopathy (PVR). The next layer of cells in the retina which contain the rods and cones which project into the RPE. ${ }^{8}$ Following the layer of rod and cone projections into the RPE is the outer nuclear layer which contains the cell bodies of the rods and cones. After this layer is the inner nuclear layer, followed by the inner plexiform layer, the ganglionic layer,a layer of optic nerve fibers, and the inner limiting membrane. 
Light must travel through the layers of the retina before it is able to activate the rod and cone cells of the eye. ${ }^{9}$ After activating the cells through the absorption of photons the light is converted into a biochemical message that is further modified into an electrical signal which is transduced to the nervous cells of the retina and then relayed to the brain. The retinal pigment epithelium (RPE) lining the posterior portion of the eye is integral in the development of PVR.

The RPE is a monolayer of cells that is part of the blood retinal barrier. ${ }^{9}$ It plays a wide variety of roles in maintaining the retinal environment for the rods and cones which it intimately interacts with. The basolateral membrane of the RPE faces Bruch's membrane. Microvilli on the apical surface of the RPE complex with the outer portions of the photo receptors and work to maintain the retinal microenvironment necessary for vision.

One of the RPE's functions which is necessary for sight in the human eye is the absorption of light which is focused on the retina by the lens. ${ }^{9}$ The RPE forms a dark pigmented wall which aids in the absorption of scattered light. Another function of the RPE is ion transport between the photoreceptors of the eyes and the choriocapillaries. The large amount of metabolic turn over in the retina and intraocular pressure from the vitreous body to the retina produces water which must be removed from the retinal space. Water from the inner retina is transported by the Müller cells and water from the subretinal space is removed by the RPE. The RPE transports water and ions from the subretinal space into the choriocapillaries. In addition to moving water and ions the RPE also removes metabolic waste products produced by the photoreceptors.

Along with transporting water and electrolytes from the subretinal space to the choroid, the RPE also transports glucose and other nutrients from the blood to the 
photoreceptors of the eye. ${ }^{9}$ The RPE maintains the excitability of the rods and cones by transporting all-trans-retinal and isomerizing it to all-cis-retinal before returning it to the photoreceptors. Photoreceptor excitability is also maintained through the phagocytosis of worn out photoreceptors by the RPE. The RPE also secrets growth factors and immunosuppressive factors into the eye. The RPE plays many vital functions in the eye and a disruption in any one of the functions can result in damage to the retina and loss of vision.

\section{B. Proliferative Vitreoretinopathy}

The Retina Society Terminology defined proliferative vitreoretinopathy as the growth of cellular membranes on the anterior and posterior surfaces of the detached retina and the posterior hyaloids. ${ }^{\mathbf{1 0 , 1 1}}$ PVR is marked by the migration of cells onto the retinal surfaces in response to chemical signals associated with wound healing. The disease process can be divided into several stages: cell migration and proliferation, extracellular collagen production and membrane development, and contracture of membrane that causes folding and/or detachment of the retina. ${ }^{12}$ This contracture of the retina proceeds tractional retinal detachment and is the most common cause for retinal detachment following surgical interventions. ${ }^{13}$ In 1981 the Retina Society Terminology classified the physiological conditions previously known as massive vitreous retraction (MVR), massive preretinal retraction (MPR), massive periretinal proliferation (MPP) and massive preretinal fibroplasia (MPF) under the name of PVR and classified the disease into grades of severity. ${ }^{14}$

Retinal detachment from the underlying retinal pigment epithelium (RPE) can be caused by traction forces on the retina or impairment of RPE pump function. ${ }^{15,16}$ Such 
detachment causes tissue trauma and induces inflammatory and wound healing responses of the body that can lead to PVR..$^{11,17,18}$ Several cell types have been implicated to play roles in PVR including: retinal pigment epithelium, mononuclear leukocytes, microglia, and Müller glia. In the first few days following retinal injury, proliferation of Müller cells occurs. ${ }^{16}$ In the normal retina, Müller glial cells cover the entire retina, providing it with structural and metabolic support. In response to injury, reactive Müller cell gliosis occurs and is thought to be a protective mechanism to prevent further tissue damage and promote retinal repair. This response by the Müller cells is associated with the release of proinflammitory cytokines and growth factors, which in the adult mammalian retina can lead to further degeneration and damage.

The RPE is a single layer of cells that lines the Bruch's membrane. RPE cells gain access to the vitreous cavity through retinal holes and/or tears that often accompany retinal detachment. ${ }^{19}$ Loss of cell-cell adhesion triggers cells to undergo an epithelialmesenchymal transition (EMT) rendering them similar to fibroblasts in morphology. This transition changes epithelial cells phenotypes to display one associated with mesenchymal cells including increased mobility, resistance to apoptosis, increased ECM production, and greater invasive properties. ${ }^{20,21}$ These cells are further stimulated to proliferate by a combination of growth factors/cytokines from the vitreous and inflammation that includes transforming growth factor beta (TGF- $\beta$ ), platelet-derived growth factor (PDGF), and thrombin. ${ }^{22}$

Both activated Müller cells and RPE cells that have undergone EMT can further be induced to become myofibroblasts, which are positive for strongly contractile $\alpha$-smooth 
muscle actin ( $\alpha$-SMA). ${ }^{23}$ Myofibroblasts are considered to play a critical role in various fibrotic diseases including PVR.

Various growth factor receptors such as platelet-derived growth factor receptors (PDGFR) have been found in the epiretinal membranes formed in PVR. ${ }^{24,25}$ Kazlauskas and colleagues have conducted a series of studies demonstrating the importance of PDGFR- $\alpha$ in PVR associated cellular functions in vitro and in a rabbit model of PVR in vivo. Such receptors can be targeted molecularly through the use of pharmaceutical agents, including the drug dasatinib. ${ }^{26}$ Targeting these cellular growth factors may be used to prevent or slow the formation of PVR in the eye.

\section{Current Treatments and Limitations}

Surgery is currently the preferred method of treatment for PVR. ${ }^{12}$ The aim of retinal surgery is to alleviate retinal traction and repair the break in the retina to reinstate as much healthy retinal anatomy as possible. The most common procedure performed for PVR is pars plana vitreoctomy with membrane peeling. ${ }^{15}$ Light to moderate cases of PVR are most easily treated with surgery, while severe PVR requires complicated surgery, as examined by Mendes, e. $a l .^{27}$ The study evaluated retinectomy to treat severe proliferative vitreoretinopathy. Thirty-eight patients with PVR grade C3, which is considered severe PVR, underwent retinectomy which increased the rates of final retinal reattachment. Various drugs and pharmacological agents including anti-inflammatory drugs, antiproliferative agents, and growth factor pathway inhibitors. 
Anti-inflammatory drugs are commonly used to try to prevent PVR. ${ }^{12}$ Proteometric analysis of the vitreous samples of patients with PVR has shown up-regulation of inflammatory markers. Triamcinolone (a glucocorticoid) was first used by Jones, et al. along with pars plana vitrectomy (PPV) and silicone oil with conflicting results. Prednisone is another anti-inflammatory commonly used to treat this physiological condition, but requires further research to determine its efficacy. Other pharmacological agents that have been used to treat the disease among which is 5-fluorouracil an antiproliferative agent.

Antiproliferative agents have been used to treat PVR with mixed results. ${ }^{13}$ Antiproliferative agents are used to inhibit the cell cycle and cellular proliferation of RPE cells following the break in the retina. The most commonly used antiproliferative agent is 5-fluorouracil (5-FU). It inhibits thymidine formation, thereby preventing DNA synthesis in actively proliferating cells. When used in clinical trials 5-FU was shown to reduce the rate of postoperative PVR following rhegmatogenous retinal detachment surgery $(\mathrm{RRD}){ }^{29}$

Cellular growth pathway inhibitors, such as those that interfere with kinase enzymes, are another method being examined to control PVR. ${ }^{13,30}$ Kinases participate in transducing extracellular signaling into gene expression changes such as EMT. Inhibiting signaling pathways involved in PVR has been shown to prevent EMT, thus preventing formation of the epiretinal membrane. ${ }^{20}$ Ranibizumab, a vascular endothelial growth factor inhibitor, has been shown to prevent PVR in rabbit models. ${ }^{15}$ Kinase inhibitors work later in the cell signaling pathway and may halt the PVR process. 


\section{Dasatinib and Proliferative Vitreoretinopathy:}

Dasatinib is a dual tyrosine kinase inhibitor developed to inhibit SRC family kinases and Abl kinase. ${ }^{31}$ Dasatinib is currently Food and Drug Administration (FDA) approved for the treatment of chronic myeloid leukemia under the trade name of Sprycel. ${ }^{32,33}$ Umazume, et al. tested dasatinib's ability to prevent the PVR-associated cellular changes on cultured RPE cells from swine. ${ }^{34}$ A porcine in vivo model for PVR was subsequently used to evaluate the level of retinal traction in the eye caused by PVR. Dasatinib was shown to prevent RPE growth in a dose-dependent manner with a dose of $0.1 \mu \mathrm{M}$ inhibiting $80 \%$ of vitreous fluid-stimulated collagen gel contraction. A total of eleven porcine eyes were injected with dasatinib to look at the formation of the retinal membrane and retinal traction. Due to the low residence time of dasatinib in the vitreous humor, injections were made into the eyes on day $0,3,7$, and 10 . Only one of the eleven eyes injected with dasatinib presented with retinal detachment while all eleven control eyes had retinal detachment. The use of multiple injections of dasatinib to prevent the formation of PVR makes the drug an ideal candidate for a drug delivery system which would remove or lower the need for frequent injections. 


\section{E. Ocular Drug Delivery}

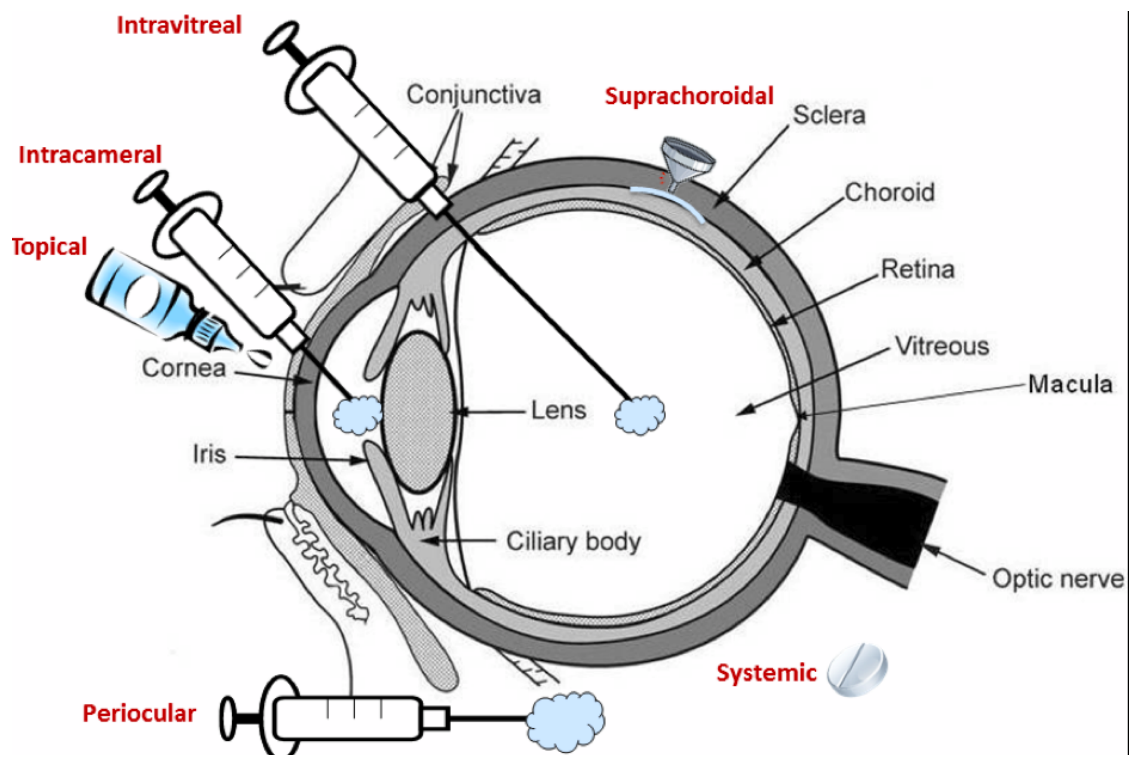

FIGURE 4. Routes of ocular drug delivery ${ }^{35}$

Drugs can be targeted to the eye through several different routes: intravitreal, subconjunctival, systemic application, and topical application among others. ${ }^{36}$ PVR is a disease that affects the retina, which is therefore the primary target area for drugs intended to prevent PVR pathology. The retina has several barriers that make drug delivery challenging. ${ }^{37}$ The blood retinal barrier $(\mathrm{BRB})$ is the posterior barrier to drug delivery and the blood aqueous barrier $(\mathrm{BAB})$ is the anterior barrier for drug delivery to the retina. ${ }^{\mathbf{3 8}}$ The $\mathrm{BRB}$ restricts the permeability and diffusion of substances between the retina and the blood. It relies primarily on active transport to move substances across the barrier making passive drug diffusion difficult. ${ }^{30}$ The BAB is composed of the ciliary epithelium and the capillaries of the iris. Like the BRB its function is to tightly regulate substances that can get into the eye which makes drug delivery difficult.

Topical drug delivery is appealing for drug delivery to the anterior portion of the eye (aqueous humor, iris-ciliary body, and lens), however, it has low bioavailability when 
diffusing through the layers of the eye to reach the retina. ${ }^{37}$ Less than $5 \%$ of the delivered topical dose has been shown to reach the deeper layers of ocular tissue. ${ }^{39}$ Additionally, enzymatic degradation of the drug occurs before it can reach the posterior segment of the eye.

Systemic drug delivery typically has low ocular bioavailability of the drug, with between $1-2 \%$ reaching the posterior portion of the eye. The lack of drug reaching the posterior segment of the eye requires frequent injections to sustain necessary therapeutic levels. Systemic drug delivery also allows nonspecific absorption of the drug by other tissues.

Drugs delivered into the eye cavity through periocular injection typically do not reach the retina because it lies behind the lens which acts as a barrier. ${ }^{36}$ The sclera of the eye provides a large surface area, though it has extensive blood vessel networks through which drugs can diffuse and be removed through before reaching the retina.

Intravitreal injection is the most common method of drug injection to reach the posterior segment of the eye including the retina. ${ }^{39}$ Intravitreal injections have several shortcomings, however, such as the need for repeated injections. ${ }^{37}$ One of the ways researchers have tried to combat this problem is through increasing the drug residence time in the vitreous humor using a drug delivery vehicle.

\section{F. Controlled Drug Release}

Controlled drug release systems are an advancement in drug delivery technology that enables targeting of specific parts of the body while limiting systemic drug exposure, 
increasing the ability of drugs to cross physiological barriers, prolonging drug release in situ and helping prevent premature release of the drug. ${ }^{36}$ The increased efficiency in delivering drugs to their target can be used to decrease the overall drug dosage and the amount of the drug needed for therapeutic levels.

Nanoparticles/sub-micron particles, ranging in size from $10-1000 \mathrm{~nm}$, have been researched extensively for use as drug delivery systems. For ophthalmologic drug delivery, particles are typically composed of either lipids, proteins, or polymers. ${ }^{39}$ Nanoparticles have been used for a long-term drug delivery solution to the posterior components of the eye. Once injected into the vitreous humor of the eye nanoparticles have been shown to accumulate on the RPE. The various drug release profiles of particles can be divided into slow sustained release and particles that experience a burst release followed by sustained release. ${ }^{40}$ The zero-order model of drug release kinetics is for nanoparticles which do not undergo disintegration and release the drug at a slow steady rate until no drug remains. The first order model of drug release kinetics can also be used to describe particles which did not experience an initial burst release and is typically seen in water soluble drugs in a porous matrix. The Higuchi model of drug release was first elucidated in 1961 and was used to describe drug release kinetics from planar systems. Takeru Higuchi developed the model based on drug release from thin ointment films which is modelled as drug release into a perfect sink. ${ }^{41}$ The Higuchi model of drug release is best used to predict drug release from a permeable matrix when the amount of drug released is greater than the solubility limit. ${ }^{42}$ The model, however, has since found utility in characterizing drug release in particles as well. The Hixon-Crowell model of drug release is used when the drug release is parallel to the surface on which dissolution will take place. Its application primarily 
exists in dissolvable tablets for drug delivery. The Korsmeyer-Peppas model of drug delivery was developed for drug release from a polymeric system. In addition to the above drug release kinetics, there are several "special application" models which have not been covered.

Particles employed for ocular drug release have shown a variety of drug release kinetics models. For example, chitosan sodium alginate nanoparticles used for ocular drug delivery were found to have an initial burst release followed by a longer sustained drug delivery period. ${ }^{43}$ Another set of chitosan nanoparticles loaded with cyclosporine A for the treatment of extraocular disease were also found to have an initial burst release followed by sustained drug release. ${ }^{44}$ Poly (lactic-co-glycolic) acid (PLGA) nanoparticles loaded with cyclosporine A showed a biphasic drug release profile and fit a Weibull model of drug release. ${ }^{45}$

Three of the most common polymers for ocular drug delivery are: poly (alkyl cyanoacrylates), polycaprolactone, and poly (lactic-co-glycolic acid). ${ }^{46}$ PLGA is a biodegradable, nontoxic polymer that hydrolyzes into the nontoxic monomers lactic acid and glycolic acid. PLGA nanoparticles have been used to deliver drugs to the retina. ${ }^{47}$ One of the advantages of using PLGA as a drug delivery system is the tailorability of the drug to the needs of the research team. ${ }^{48}$ The release time of drugs encapsulated in a PLGA shell can be modified by varying the molecular weight of the polymer, the lactide:gylcolide ratio of the polymer, and altering how the polymer/drug is combined.

Gupta, et. al. used PLGA to deliver sparfloxacin to improve precorneal penetration time and increase the amount of drug in the vitreous humor. ${ }^{46}$ Gavini, et. al. utilized PLGA microspheres to deliver vancomycin using spray drying manufacturing methods. ${ }^{49}$ The 
research team found that the preparation of PLGA drug delivery vehicles was a suitable method of drug delivery. Gupta, et. al. used PLGA nanoparticles loaded with the drug sparfloxacin for ocular drug delivery for treatment of bacterial conjunctivitis. ${ }^{46}$ PLGA nanoparticles have been shown to increase the ocular bioavability of drugs in the eye but must be produced at a specific size range to prevent ocular irritation while still delivering enough of the drug to treat the desired condition. Particle size and polydispersity were found to influence the delivery of Sparfloxacin to the eye. PLGA nanoparticles under 250 nm were considered optimal for ocular drug delivery. Ocular irritation was tested through the use of hen's egg chorioallantoic membrane tests. Membrane tests were performed because they are sensitive, inexpensive and the chorioallontic membrane is a whole tissue that includes veins, arteries, and capillaries. Being a complete tissue, the chorioallontic membrane responds with a total inflammatory response and is an appropriate method of observing what biological reactions would occur in the eye.

Another study by Chang, et al. looked at the biocompatibility of PLGA nanoparticles for ocular drug delivery. ${ }^{48}$ Albumin and doxycycline were fluorescently labeled and loaded into PLGA using a water-oil-water double emulsion method. Subconjunctival injections were used to evaluate the biocompatibility of PLGA particles with the eye in murine animal models. The mice in the study received conjunctival injections of $10 \mu \mathrm{L}$ in both eyes and were euthanized after 14 days to observe the immune response to the particles. Particles were found to be biocompatible and no significant ocular inflammation was found. Drug release of the particles was also observed. The particles exhibited an initial burst release followed by a slow sustained release out to 20 days, indicating efficacy as a longer-term drug delivery product. Abrego, et al. looked at PLGA 
particles loaded with pranoprofen for ocular drug delivery. ${ }^{50}$ The nanoparticles were synthesized using a solvent displacement technique with polyvinyl alcohol as a stabilizer. Ocular tolerance was tested using HET-CAM, and an irritation level of zero was obtained.

As can be seen from the above studies, PLGA is a drug delivery system that allows customization based on the manufacturing parameters, the polymer itself and the drug utilized. The tailorability of PLGA as well as the low levels of ocular irritation found previously makes it an attractive drug delivery vehicle. There are several manufacturing methods in which PLGA nanoparticles can be manufactured. In this project, PLGA nanoparticles were synthesized using the spray drying manufacturing method which has four primary manufacturing parameters that can be controlled: PLGA concentration (w/v\%), inlet temperature, flow rate, and lactide:gylcolide ratio of the PLGA.

\section{G. Spray Drying Manufacturing Method}

The spray drying manufacturing method of producing nanoparticles has a welldocumented history in scientific literature. It is a popular method to produce nanoparticles in both research and in industry. ${ }^{52}$ Spray drying generates solid powders through the fast drying of the carrier solvents. ${ }^{53,54}$ Understanding and controlling nanoparticle production has gained more interest in the last decade. ${ }^{55} \mathrm{~W}$ ith the increase of research in nanoparticles the spray drying manufacturing method has received more attention as a manufacturing method of nanoparticles for drug delivery. Particles produced via spray drying are known to have a primarily spherical morphology with few exceptions. 
Use of the Büchi Nano B-90 has been shown to produce particles that are spherical with a high particle yield of up to $85 \%$ using a small amount of starting material. ${ }^{56}$ The Büchi B-90 has a vibrating mesh and an electrostatic particle collector which allow better control of the spray drying process. ${ }^{53,47}$ The mesh can reliably generate similarly sized nanoparticles and the electrostatic particle collector ensures a better yield. There are several parameters on the Büchi B-90 that can be controlled and changed when producing particles. Two of the parameters for this experiment were optimized using the Büchi B-90 including the air flow rate through the spray dryer and air inlet temperature, which indirectly controls the temperature of the spray head. The other variables in the experiment were based on the PLGA concentration and the amount of dasatinib used. Optimization of particle production using a Büchi B-90 has been previously attempted by Sree Harsha, et. al. To create particles of vitaglpitin, a new drug for diabetes, spray drying was optimized using three factors and observing their effect on the formulation of the particles. ${ }^{57}$ However, optimization of the spray drying process is sensitive to several factors, and thus must be repeated for each set of drug/polymer/solvent combinations.

Lee et al. looked at the optimization of the spray drying of bovine serum albumin (BSA) for particle size and axial morphology on a Büchi B-90 using a Taguchi design approach. ${ }^{58}$ The levels that were used in this experiment were: spray mesh pore diameter, BSA solution concentration, surfactant concentration, drying air flow rate, and inlet temperature. The parameters that were found to have the most effect were spray mesh size and surfactant concentration. Lee, et. al. proved that nanoparticles sprayed on a Büchi B90 can successfully be optimized to hit the desired target parameters using a logical engineering approach through the use of a Taguchi design. 


\section{$\underline{H}$. Instrumentation and Equipment}
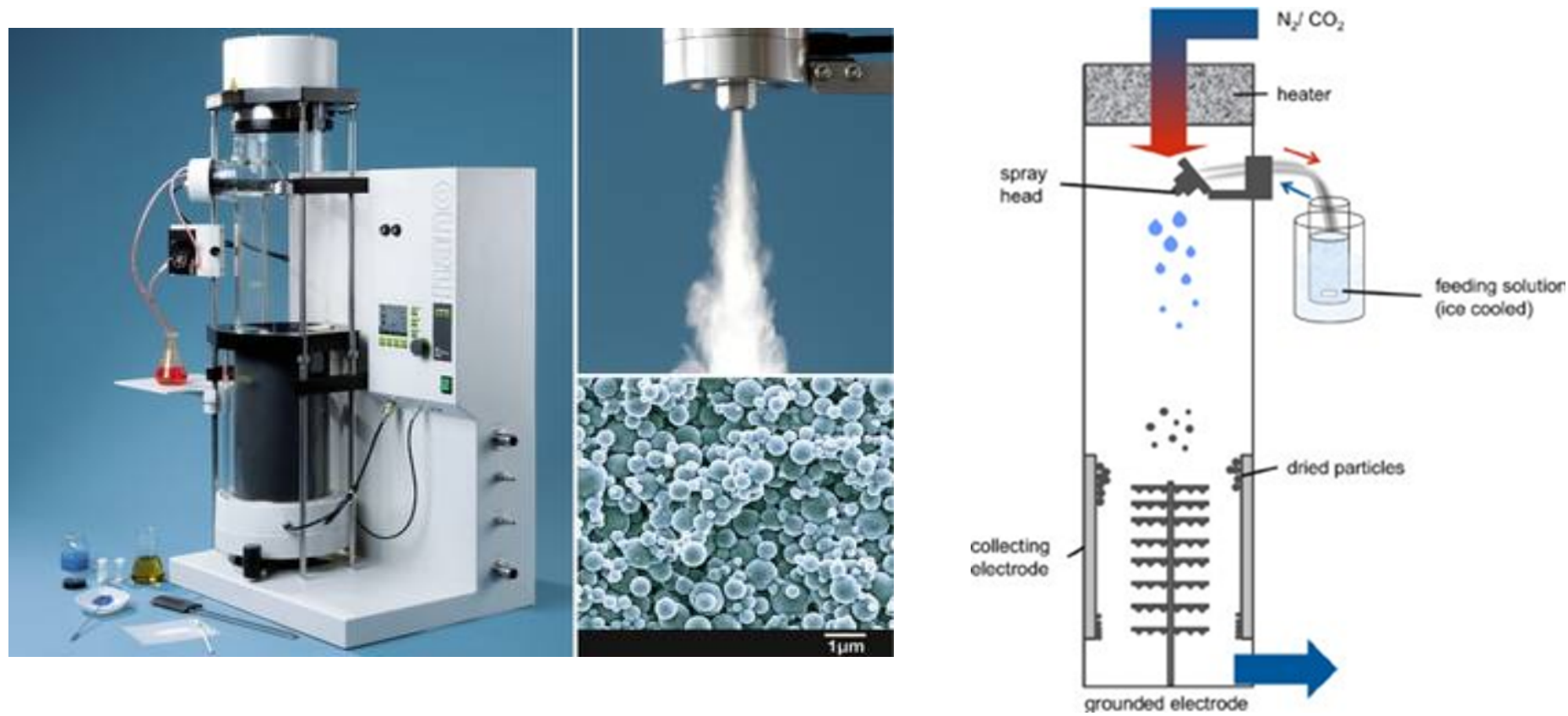

FIGURE 5. Büchi B-90 nano spray dryer ${ }^{59,60}$

A Büchi B-90 nano spray dryer (Büchi, New Castle, DE.) was used to spray dry the PLGA and PLGA dasatinib (PLGA-D) particles (figure 5). There are several functional elements of the spray dryer that perform tasks necessary for particle formation. ${ }^{61}$ At the top of the spray dryer there is a heating element and the spray head itself. The heating element heats the inlet air to the desired temperature and can produce temperatures up to $120^{\circ} \mathrm{C}$. Droplet formation is achieved through the use of an ultrasonic nebulizer.

The ultrasonic nebulizer is in the spray head. It includes a piezoelectric actuator with a thin stainless-steel membrane that contains micron-sized pores. Different sized meshes having different average pore diameters allows the user to select a mesh to achieve 
the desired particle size. This stainless-steel membrane vibrates at ultrasonic frequencies between $80-140 \mathrm{kHz}$ which ejects droplets at the desired size. The droplets next encounter the drying chamber, which uses conductive heat exchange between the drying gas and the droplets. ${ }^{52}$ Particles form from the droplets as the solvent evaporate and are collected by an electrostatic particle collector located at the base of the spray drying unit. The Büchi B90 Nano spray dryer also contains an outlet filter that collects the finest particles for protection of the user and the environment. The drying gas is pumped into the drying chamber via either an aspirator or compressed air, with the air flow rate controlled via an inlet regulator.

For the spray drying of PLGA and PLGA-D, a flammable organic solvent, dichloromethane, was utilized. This required the spray dryer to be operated with a Büchi B-295 Inert Loop system that allows the spray dryer to be operated with the exclusion of oxygen in the inlet gas. This prevents ignition of the solvent vapor, and also allows solvent recycling and reduces cost.

As stated previously the Büchi B-90 can be optimized through careful experimental design to determine which parameters contribute the most to particle size. ${ }^{62}$ Spray drying on a Büchi B-90 presents a unique challenge because the machine has several different components which can be optimized. Additionally, the PLGA and dasatinib concentrations can also be studied to observe their effect on final particle size. Given the large number of variables, a rational design is needed such as the Taguchi design like the one used by Lee, et. al. to spray bovine serum albumin. 


\section{Taguchi Matrix and Taguchi Design:}

Design of experiments can be used to optimize a procedure, however, once several variables become involved it becomes increasingly difficult and costly to perform. Taguchi matrix design allows for the optimization of manufacturing parameters through the control factors of the experiment. Taguchi design was developed by Dr. Genichi Taguchi and is a technique which reduces the number of experiments through an orthogonal array and minimization of out of control factors. Originally, it was used for improving the quality of manufactured goods but has found application in other fields such as engineering and biotechnology. ${ }^{64}$

Taguchi design reduces the number of experiments that need to be performed and utilizes orthogonal arrays to achieve this. Orthogonal arrays are used to analyze many design factors simultaneously. ${ }^{53} \mathrm{~A}$ loss function is used to measure the performance characteristics that are deviating from the desired value. ${ }^{64}$ The value obtained from the loss function is transformed into a signal-to-noise $(\mathrm{S} / \mathrm{N})$ ratio. The $\mathrm{S} / \mathrm{N}$ value measures the quality of the manufactured product with emphasis on product variation. Typically, the

designated trials from the Taguchi matrix are performed, and the set of parameters that minimizes the $\mathrm{S} / \mathrm{N}$ ratio for the desired outcome (in our case particle size) is selected. 


\section{II.PROCEDURE}

\section{$\underline{\text { A. Chemical Supplies }}$}

PLGA with three different lactide:gylcolide ratios $(65: 35,50: 50,75: 25)$ was purchased from Lactel Absorbal Polymers (Birmingham, AL). Dichloromethane and phosphate buffered saline pH 7.4 (PBS) were supplied by Sigma-Aldrich (St. Louis, MO). Dasatinib was supplied by Toronto Research Chemicals (Ontario, Canada).

\section{B. Synthesis of PLGA and PLGA Dasatinib Solution:}

PLGA particles of various lactide:glycolide ratios were dissolved in dichloromethane at various weight by volume $(\% \mathrm{w} / \mathrm{v})$ depending on the parameter requirements in the Taguchi matrix (Table 1). This mixture was then sonicated for 10 minutes to ensure full dissolution of the PLGA into the DCM. The solution was kept on ice while being spray-dried.

\section{Spray Drying of PLGA Based on Taguchi Design:}

PLGA and PLGA dasatinib solutions were spray dried using a Büchi B-90 Nano spray dryer. Four parameters were manipulated to see what combination would yield the smallest PLGA particle size. The parameters that were manipulated were: PLGA concentration $(\mathrm{w} / \mathrm{v})$, lactide:glycolide linkage ratio of the PLGA, spray head inlet temperature, and the flow rate of the spray dryer. These parameters were chosen based on

prior spray dries performed in the lab previously and by others. Schafroth, et al. also utilized a Büchi 90 Nano spray dryer with PLGA dissolved in DCM and analyzed the effect 
of inlet temperature, flow rate, lactide:glycolide ratio on PLGA particles.$^{65}$ They found that the spray mesh diameter, sample flow rate, spray rate, and sample concentration had a profound effect on the size of the PLGA particles produced providing another example that spray drying parameters can be manipulated to optimize particle size.

\section{TABLE I.}

\section{PARAMETERS FOR SPRAY DRYING PLGA PARTICLES}

\begin{tabular}{|c|c|c|c|c|}
\hline PARAMETER & DETAILS & & LEVEL & \\
\hline & & 1 & 2 & 3 \\
\hline A & PLGA concentration (w/v\%) & 1.5 & 2 & 2.5 \\
\hline B & Inlet temperature $\left({ }^{\circ} \mathrm{C}\right)$ & 40 & 45 & 50 \\
\hline C & Flow rate (L/min) & 95 & 100 & 110 \\
\hline D & $\begin{array}{c}\text { PLGA Ratio } \\
\text { (lactide:glycolide) }\end{array}$ & $50: 50$ & $65: 35$ & $75: 25$ \\
\hline
\end{tabular}

The parameters that were used were as follows: PLGA $(\mathrm{w} / \mathrm{v} \%)=1.5 \%, 2.0 \%$, 2.5\%; Inlet temperature $\left({ }^{\circ} \mathrm{C}\right)=40^{\circ}, 45^{\circ}, 50^{\circ}$; Flow rate $(\mathrm{L} / \mathrm{min})=95,100,110$; PLGA (lactide: glycolide ratio) $=50: 50,65: 35,75: 25$. Level values for each parameter were chosen based on Sree Harsha, et. al. and prior experiments in the O'Toole lab. A total of nine different spray-drying runs were performed based on the combinations produced in the Taguchi matrix. All nine PLGA sprays were done through a $4 \mu \mathrm{m}$ spray mesh, as this has consistently produced smaller particles in the lab than the other available mesh sizes. 
Table 1 shows the levels and parameters that were used for PLGA spray drying runs based on the Taguchi matrix.

TABLE II.

\section{TAGUHI MATRIX DESIGN RUNS AND LEVELS}

$\begin{array}{lrllll} & \begin{array}{l}\text { PLGA Concentration } \\ (\mathrm{w} / \mathrm{v} \%)\end{array} & \begin{array}{l}\text { Inlet } \\ \text { Temperature }\left({ }^{\circ} \mathrm{C}\right)\end{array} & \begin{array}{l}\text { Flow Rate } \\ (\mathrm{L} / \mathrm{min})\end{array} & \begin{array}{l}\text { PLGA (Lactide:Glycolide } \\ \text { Ratio })\end{array} & 1 \\ \text { Run 1 } & 1 & 1 & 1 & 2 \\ \text { Run 2 } & 1 & 2 & 2 & 3 \\ \text { Run 3 } & 1 & 3 & 3 & 3 \\ \text { Run 4 } & 2 & 1 & 2 & 1 \\ \text { Run 5 } & 2 & 2 & 3 & 2 \\ \text { Run 6 } & 2 & 3 & 1 & 2 \\ \text { Run 7 } & 3 & 1 & 3 & 3 \\ \text { Run 8 } & 3 & 2 & 1 & 1 \\ \text { Run 9 } & 3 & 3 & 2 & & 3\end{array}$

Dry particles were collected from the collecting drum using a nanoparticle scraper manufactured by Büchi.

\section{Spray Drying of PLGA Based on Best Taguchi Design}

Following optimization, PLGA particles were spray-dried using the parameters in the Taguchi matrix that yielded the smallest particle size, which was trial 1. Based on analysis of the original Taguchi results three more spray drying trials of just PLGA were completed using lower percent weight by volume ( $\mathrm{w} / \mathrm{v} \%)$. The $\mathrm{w} / \mathrm{v} \%$ variations were: $0.25 \%, 0.5 \%$, and $1 \%$ with all other parameters held the same as in trial

\section{E. Spray Drying of PLGA Dasatinib Particles}

PLGA dasatinib (PLGA-D) particles were produced using the same method as the particles manufactured for the Taguchi optimization with the further synthesis step of the addition of dasatinib. PLGA and dasatinib were dissolved in DCM using the parameters of 
the PLGA particles from Trial 1 which yielded the smallest particles. $0.025 \%$ dasatinib $\mathrm{w} / \mathrm{v} \%$, and 0.5\% 50:50 PLGA were used in the synthesis of the new PLGA-D particles. Dasatinib was then added to the PLGA/DCM mixture. The solution was then sonicated for 10 minutes to ensure full dissolution of the PLGA and dasatinib in the DCM.

PLGA dasatinib particles were spray dried using the following parameters: $40^{\circ} \mathrm{C}, 95 \mathrm{~L} / \mathrm{min}$ flow rate, $0.5(\mathrm{w} / \mathrm{v} \%)$ 50:50 PLGA, and $0.025(\mathrm{w} / \mathrm{v} \%)$ dasatinib. These parameters were chosen because they yielded the smallest PLGA particles. Different w/v $\%$ of dasatinib were loaded into the particles to see how dasatinib loading affected particle size and morphology.

\section{F. Particle Characterization:}

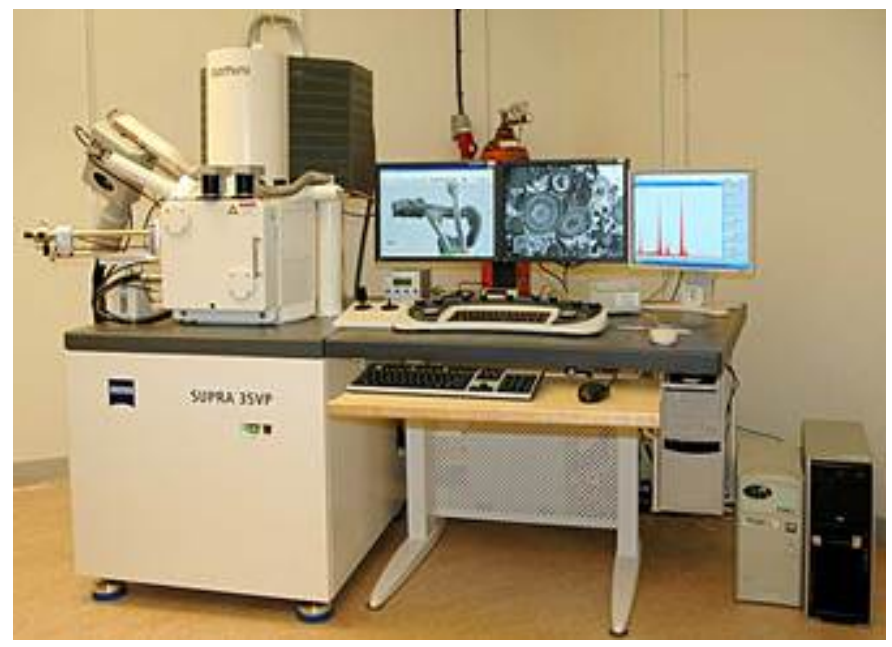

FIGURE 6. Zeiss Supra 35 SEM microscope ${ }^{65}$

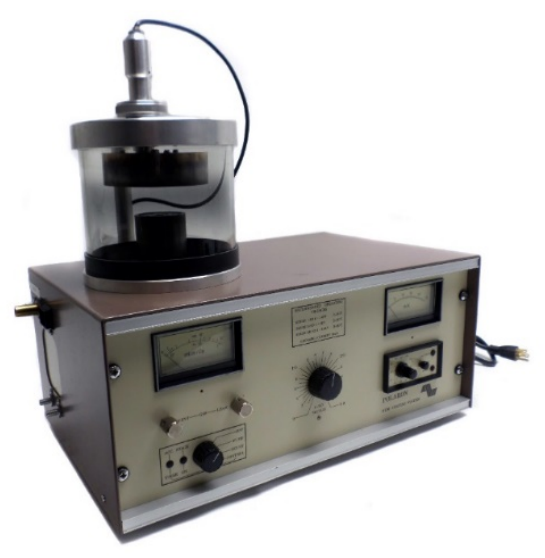


FIGURE 7. Plasma coater ${ }^{65}$

All particles were characterized using a Zeiss Supra 35 field emission scanning electron microscope (Carl Zeiss Microscopy, LLC, Thornwood NY) shown in Figure 6. Samples were prepared on SEM sample tacks and sputter coated for 30s with gold/palladium using a plasma coater from International Scientific Instruments (New Dehli, India seen in Figure 7. Images from the SEM were taken using EHT $=2 \mathrm{kV}$. ImageJ software was utilized to analyze the particle diameter. ${ }^{67}$ For each Taguchi trial, a total of ten different images were used with 100 particles being measured per image for a total of $\mathrm{n}=1000$ particles. SEM images of the Taguchi trials can be seen in the appendix. Particle diameter was based on the longest axial measurement of the particle. Statistical comparison of particle size was performed using student t-tests with a p-value of 0.05 .

The second optimization set of PLGA particles utilizing differing $\mathrm{w} / \mathrm{v} \%$ PLGA were characterized using a minimum of 100 particles per image with at least five different SEM images used per condition. PLGA-D particles were characterized with a minimum of 1000 particles per condition.

In addition to the SEM images, particle stability in 1x PBS was analyzed using zeta potential measurements on a ZetaPALS (Brookhaven). Higher absolute Zeta potential values were interpreted to correlate with higher particle stability.

\section{G. Statistical Analysis of Particle Size and Morphology:}


PLGA particle size optimization was performed through the use of a Taguchi matrix. The parameters that were optimized can be seen in Table 1. Each parameter that was optimized had three different levels which were chosen based on prior spray drying done with PLGA in the O'Toole lab as well as other laboratories. Particle optimization was based on minimizing particle diameter. Particle sizes were measured using ImageJ software calibrated to the $10 \mu \mathrm{m}$ scale bar on the SEM images. Signal-to-noise ratio $(\mathrm{S} / \mathrm{N})$ was used to quantify particle optimization:

$$
(S / N)_{i}=-10 \log _{10}\left[\sum_{n}^{i=1}\left(y_{i}^{2} / n\right)\right]
$$

where $\mathrm{n}$ is the number of observations (in this case the number of particles measured utilizing IMAGE $\mathrm{J}$ ) and $\mathrm{y}$ is the output that is being measured (particle size). The $\mathrm{S} / \mathrm{N}$ ratio is used in the Taguchi design to identify the set of parameters that produce the desired product with the least amount of noise.$^{68}$ Noise is uncontrollable variability inherent to a manufacturing procedure. The $\mathrm{S} / \mathrm{N}$ ratio shows which parameters on the Taguchi matrix produce particles with the lowest uncontrolled variation. This equation is used to minimize the occurrence of undesirable particle characteristics such as particles that are too large. ${ }^{69}$

\section{$\underline{\text { H.Dasatinib Release Studies }}$}

A zero-time point release value was collected by rinsing $7 \mathrm{mg}$ of PLGA dasatinib particles in 1x phosphate buffer solution (PBS). The PBS was then removed using a pipet and measurement of dasatinib content in the rinsed solution was measured using the UV-VIS spectrum collected on a Cary 50 bio (Varian). Dasatinib concentration was evaluated at 
absorbance of 325 nanometers (nm). New 1x PBS was then added to the PLGA dasatinib pellets and the dispersions were placed in a Thermo Scientific Series $8000 \mathrm{DH} \mathrm{CO}$ incubator at $37^{\circ} \mathrm{C}$ and allowed to sit for 24 hours. After 24 hours had passed the 1x PBS was removed utilizing a pipet and dasatinib quantified using the absorbance value at 325 $\mathrm{nm}$. Measurement of PBS and subsequent replacement of fresh 1x PBS was performed for a total of 30 days.

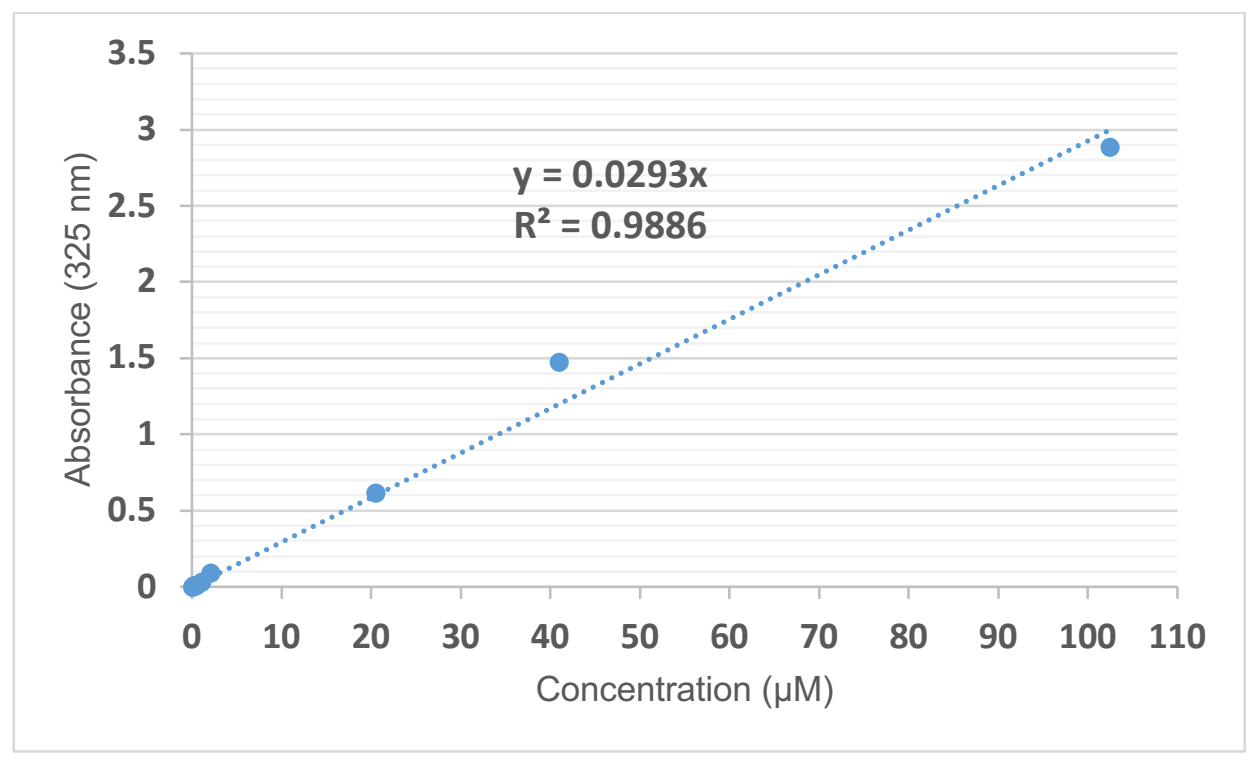

FIGURE 8. Dasatinib UV-Vis calibration curve

A calibration curve was prepared using dasatinib dissolved into 1x PBS the concentrations of dasatinib used and the corresponding UV-VIS peaks obtained from the machine can be seen in Figure 8

\section{RESULTS AND DISCUSSION}

A. Prior PLGA Dasatinib Particles 
PLGA and PLGA-D particles with sizes larger than one micrometer were produced in an earlier study in the O'Toole lab. The release profiles of the particles were studied as was their stability in 1x PBS, which presents a baseline for comparing the particles produced utilizing the Taguchi matrix for optimization. Larger particles showed greater instability in 1x PBS as measured through zeta potential. Particles greater than $1 \mu \mathrm{m}$ in size also showed varied release profiles with release of dasatinib up to 40 days with seemingly random release kinetic behavior. Larger particles also exhibited noticeable swelling and PLGA aggregation at 15 days of suspension in the PBS.

B. PLGA and PLGA-D Optimization

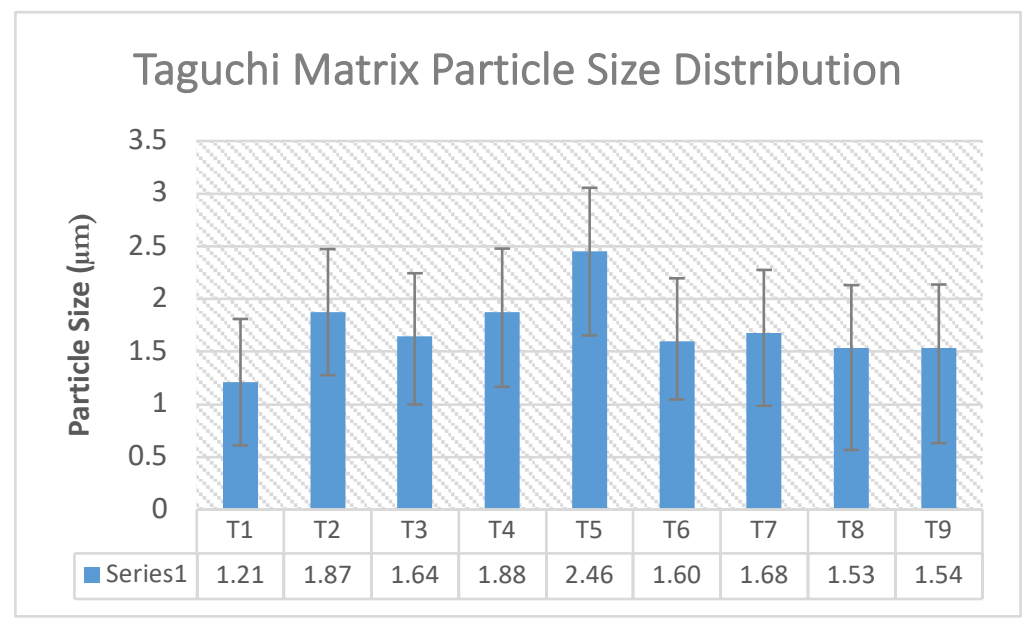

FIGURE 9. PLGA particle size distribution

A total of nine trials were performed using the Taguchi matrix. All nine trials used a $4 \mu \mathrm{m}$ mesh with dichloromethane as the solvent. 
All trials were sprayed with the PLGA DCM solution kept on ice to keep the suspension cold to reduce solvent evaporation and material degradation. Figure 9 shows a histogram of the particle sizes that were obtained. Particle size and axial ratio was measured using ImageJ software. Trial 1 produced the smallest particles with a size of $1.21 \pm 0.6 \mu \mathrm{m}$.

\begin{tabular}{|c|c|c|c|c|c|c|c|c|}
\hline \multicolumn{5}{|c|}{ PARAMETERS } & \multicolumn{2}{|c|}{ PARTICLE SIZE $(\mu M)$} & \multicolumn{2}{|c|}{ AXIAL RATIO } \\
\hline TRIAL & A & B & $\mathrm{C}$ & D & $y(n=3)$ & $\begin{array}{l}\mathrm{S} / \mathrm{N} \text { ratio } \\
(\mathrm{dB})\end{array}$ & $\begin{array}{l}y \\
(n=3)\end{array}$ & $\begin{array}{l}\text { S/N RATIO } \\
\text { (DB) }\end{array}$ \\
\hline 1 & 1 & 1 & 1 & 1 & $1.20(0.61)$ & -2.55 & 1.07 & -1.74 \\
\hline 2 & 1 & 2 & 2 & 2 & $1.87(0.60)$ & -5.87 & 1.03 & -1.61 \\
\hline 3 & 1 & 3 & 3 & 3 & $1.64(0.65)$ & -4.94 & 1.03 & -1.08 \\
\hline 4 & 2 & 1 & 2 & 3 & $1.88(0.71)$ & -6.06 & 1.09 & -2.06 \\
\hline 5 & 2 & 2 & 3 & 1 & $2.46(0.80)$ & -8.25 & 1.02 & -1.24 \\
\hline 6 & 2 & 3 & 1 & 2 & $1.60(0.55)$ & -4.51 & 1.00 & 0.01 \\
\hline 7 & 3 & 1 & 3 & 2 & $1.68(0.69)$ & -5.16 & 1.07 & -1.81 \\
\hline 8 & 3 & 2 & 1 & 3 & $1.53(0.97)$ & -4.95 & 1.10 & -1.52 \\
\hline 9 & 3 & 3 & 2 & 1 & $1.54(0.91)$ & -5.02 & 1.02 & -0.44 \\
\hline
\end{tabular}

TABLE III

PLGA particle $\mathrm{S} / \mathrm{N}$ ratio, size, and axial ration

The axial ratio of the particles is used to determine how circular the particles are by measuring diameters across the apparent largest and smallest diameters of each particle. A particle with an axial ratio measurement of 1 was considered spherical..$^{70} 5$ images with 100 particles per image (500 total) were used to measure the axial ratio. As can be seen from Table 3 all nine spray drying trials exhibited nearly spherical morphologies without significant fluctuation in particle shape. Additionally, all particles had a smooth or slightly rough surface appearance (see appendix). 
The impact of each of the four parameters used to spray dry the particles was then evaluated by averaging the $\mathrm{S} / \mathrm{N}$ ratio for all trials that shared a specific parameter level (e.g. A1). After averaging each parameter level, the range for the given parameter was determined by finding the difference between the highest and lowest $\mathrm{S} / \mathrm{N}$ ratios within the parameter.

The effect on particle size can be seen

in Table 4 and the effect on axial ratio

\begin{tabular}{c|cccc} 
LEVEL & A & B & C & D \\
\hline $\mathbf{1}$ & -4.46 & -4.59 & -4 & $\mathbf{- 5 . 2 7}$ \\
$\mathbf{2}$ & -6.27 & -6.35 & -5.65 & $\mathbf{- 5 . 1 8}$ \\
$\mathbf{3}$ & -5.04 & -5.04 & -6.12 & $\mathbf{- 5 . 3 2}$ \\
RANGE & 1.81 & 1.76 & 2.12 & $\mathbf{0 . 0 5}$ \\
RANK & $\mathbf{2}$ & $\mathbf{3}$ & $\mathbf{1}$ & $\mathbf{4}$ \\
\end{tabular}

to heightened immune response in

TABLE IV.

swine eyes with larger particles found in

Parameter level effect on particle size previous PLGA studies in the lab.

The parameters which had the largest effect on the particle size were the air flow rate of the spray dryer and the $\mathrm{w} / \mathrm{v} \%$ of PLGA used to make the particles. However, regulation

\begin{tabular}{c|cccc} 
LEVEL & A & B & C & D \\
\hline $\mathbf{1}$ & -1.48 & -1.87 & -1.08 & $\mathbf{- 1 . 1 4}$ \\
$\mathbf{2}$ & -1.10 & -1.46 & -1.37 & $\mathbf{- 1 . 1 4}$ \\
$\mathbf{3}$ & -1.26 & -0.50 & -1.38 & $\mathbf{- 1 . 5 5}$ \\
RANGE & 0.38 & 1.37 & 0.30 & $\mathbf{0 . 4 1}$ \\
RANK & $\mathbf{3}$ & $\mathbf{1}$ & $\mathbf{4}$ & $\mathbf{2}$ \\
& & & &
\end{tabular}

TABLE V.

Parameter level effect on axial ratio of the absolute air flow rate while operating the Büchi B-90 in closed loop mode is erratic. The system relies on input gas supplies from two different air cylinders $\left(\mathrm{N}_{2}\right.$ and $\left.\mathrm{CO}_{2}\right)$ and the input is only triggered after a minimum air pressure threshold is reached within the spray dryer. As a result, system pressure and resulting air flow could vary up to $50 \%$ during a single spray

drying run. Considering this, it was determined to focus on changing the PLGA concentration, as this is a much more reliable and easily controlled parameter. The 
parameters with the greatest impact on the axial ratio of the particles were the inlet temperature and lactide:glycolide ratio in the PLGA. The axial ratio measurements of the particles in Table 6 show that all of the particles exhibited an axial ratio measurements close to 1 .

Use of the Taguchi approach allowed us to identify a set of parameters within our matrix to produce the smallest particles, but more importantly, allowed us to identify which parameters had the most effect on the outcome (particle size). Due to ease of adjusting PLGA concentration, and the fact that intense immune responses were observed for larger PLGA particles when injected into our porcine models (data not shown), we decided to experiment with changing the particle size to levels outside of our original set of levels. As Trial 1 produced the smallest particles out of all of the trials, the parameters that were used for Trial 1 were $1.5 \%$ PLGA (w/v \%), $40^{\circ} \mathrm{C}$ inlet temperature, $95 \mathrm{~L} / \mathrm{min}$ flow rate, and 50:50 PLGA lactide:gylcolide linkage ratio were chosen as starting points for further experiments.

\section{TABLE VI.}

Varying PLGA w/v\% effect on particle size and axial ratio

\section{PLGA CONCENTRATION (WT/V\%)}

1.5

1.0

0.5
PARTICLE SIZE $(\mu \mathrm{M})$

$\mathrm{y}(\mathrm{n}=3)$

$1.20(0.61)$

$0.83(0.37)$

$0.73(0.40)$
AXIAL RATIO

$\begin{array}{lll}\text { SNR }(d B) & y(n=3) & \text { SNR }(d B) \\ -2.55 & 1.07 & -1.74 \\ 0.51 & 1.00 & 0.14 \\ 1.62 & 1.02 & -0.48\end{array}$

1.02

The same $\mathrm{S} / \mathrm{N}$ ratio used in our Taguchi approach was used to evaluate the impact of varying $\mathrm{w} / \mathrm{v} \%$ PLGA on the particle size while adding trials with 0.5 and $1.0 \mathrm{w} / \mathrm{v} \%$ PLGA. SEM analysis of these extra trials showed that the lower the $\mathrm{w} / \mathrm{v} \%$ of the PLGA the smaller the particle sizes that were produced, Table $6.0 .25 \% \mathrm{w} / \mathrm{v} \%$ PLGA particles were also 
produced to see the effect of lowering the particle size. $0.25 \% \mathrm{w} / \mathrm{v} \%$ PLGA particles did not have a spherical morphology and as such were not desirable to go forward with for this study images of these particles can be seen in the appendix. Particles produced with $0.5 \%$ PLGA w/v were the smallest size at $0.73 \pm 0.4 \mu \mathrm{m}$ while still maintaining a circular axial ratio of 1.02. These particles were considered most suitable for future in vivo studies, and so these spray drying parameters were used for trials in which dasatinib was included for encapsulation in the PLGA particles.
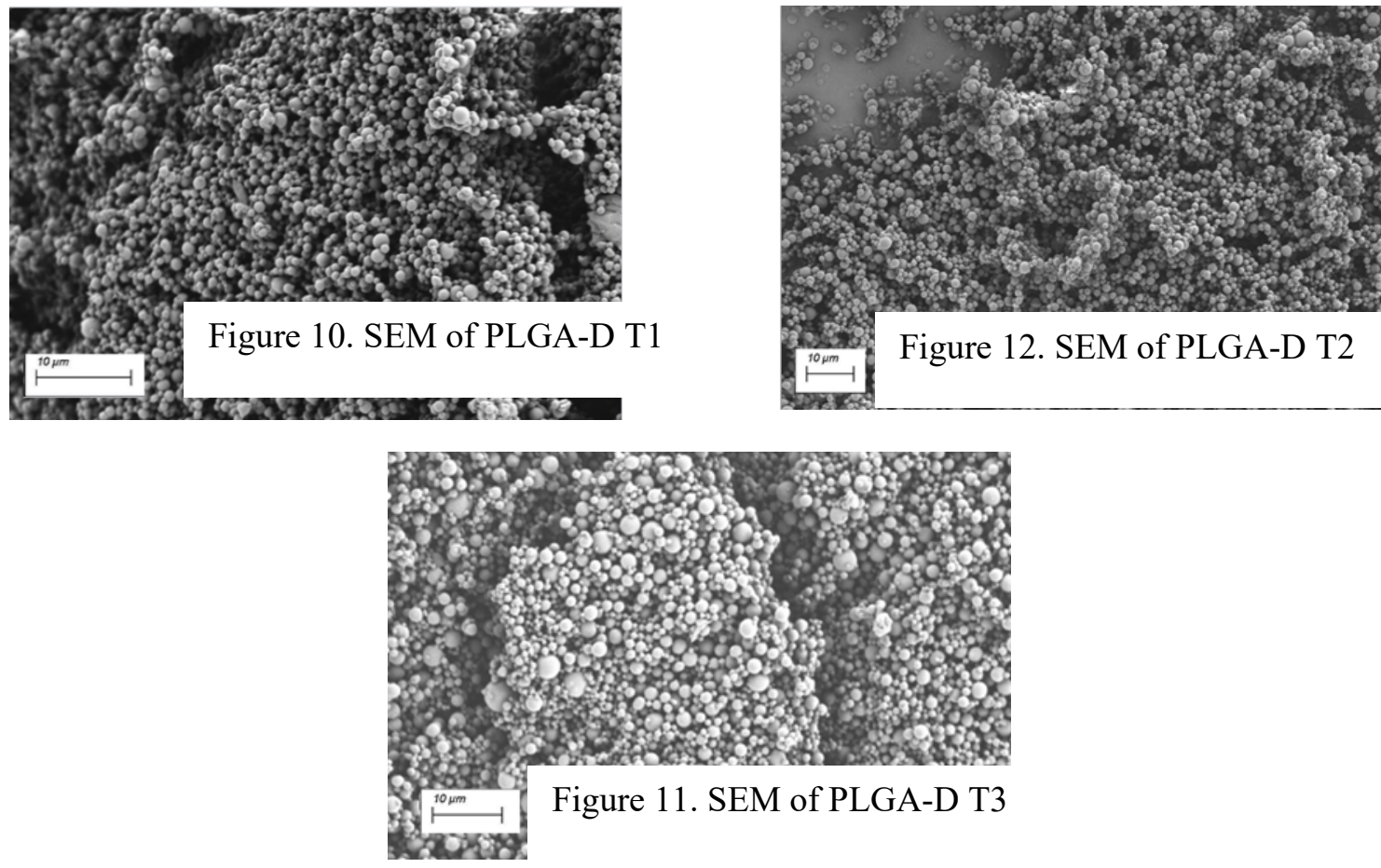

TABLE VII.

Effect of levels on PLGA-D particle size and axial ratio

\section{TRIALS PARTICLE SIZE $(\mu \mathrm{M})$ AXIAL RATIO}

\begin{tabular}{l|llll}
\cline { 2 - 5 } $\mathbf{1}$ & $\mathrm{y}(\mathrm{n}=3)$ & $\mathrm{SNR}(\mathrm{dB})$ & $\mathrm{y}(\mathrm{n}=3)$ & $\mathrm{SNR}(\mathrm{dB})$ \\
$\mathbf{2}$ & $0.76(0.32)$ & 1.64 & 1.00 & -0.15 \\
$\mathbf{3}$ & $0.73(0.35)$ & 1.89 & 1.00 & -0.48 \\
& $0.64(0.28)$ & 3.10 & 1.01 & -0.99
\end{tabular}


PLGA dasatinib (PLGA-D) particles were produced using the parameters for trial 1 with a different $\mathrm{w} / \mathrm{v} \%$ PLGA of 0.5 because it had produced the smallest particles while maintaining a spherical shape. The particles were spray dried with $0.025 \mathrm{w} / \mathrm{v} \%$ dasatinib. The concentration of dasatinib was chosen to maintain the minimum therapeutic level found in prior studies such as the one by Umazume, et. al. over the desired release period. Additionally, previous studies in the laboratory with PLGA-D showed that increasing from $0.025 \%(\mathrm{w} / \mathrm{v})$ of dasatinib up to $0.25 \%(\mathrm{w} / \mathrm{v})$ only increased the encapsulation efficiency by 1.9-2.2 times. Supporting information from the previous PLGA-D encapsulation studies can be seen in the appendix. From these experiments it was determined that using higher concentrations of dasatinib for spray drying was not cost effective. Three sets of PLGA-D particles were produced. Representative SEM images of each one of the three sets of particles can be seen in Figures 10, 11, and 12.

\begin{tabular}{c|cc} 
SUB-MICROMETER PARTICLES $(\mu \mathrm{M})$ & ZETA POTENTIAL $(\mathrm{MV})$ & STDEV(MV) \\
\hline $\mathbf{0 . 7 6} \pm \mathbf{0 . 3 2}$ & -17.32 & 4.81 \\
$\mathbf{0 . 7 3} \pm \mathbf{0 . 3 5}$ & -20.69 & 3.27 \\
$\mathbf{0 . 6 4} \pm \mathbf{0 . 2 8}$ & -29.93 & 2.11
\end{tabular}

\section{Table VIII.}

Zeta potential submicrometer particles

As can be seen from the SEM images all three sets of particles exhibited a nearly spherical morphology which is corroborated by the axial ratio measurements in Table 7 which are all close to 1 . Two sets of the particles exhibited a perfectly spherical morphology with an axial ratio score of 1.0. The last set of particles produced had an axial ratio value of 1.01 . The sizes of the particles that were produced were $0.76 \pm 0.32 \mu \mathrm{m}, 0.73$ $\pm 0.35 \mu \mathrm{m}$, and $0.64 \pm 0.28 \mu \mathrm{m}$. All three sets of particles hit a size below the 
target of $1 \mu \mathrm{m}$ and exhibited the desired spherical morphology. Hela cells were found to internalize more spherically shaped gold nanoparticles over rod shaped nanoparticles. ${ }^{19}$ Wooley, et. al. found that smaller spherical micelles had greater cellular uptake than larger spherical micelles indicating that smaller more spherical nanoparticles increase cellular uptake. Particle diameters were determined using ImageJ analysis of 8000 particles from ten different SEM images.

The three sets of submicrometer particles exhibited enhanced stability as measured by the zeta potential Table VIII when compared to previous micrometer sized particles. Table A2 in the appendix shows the zeta potential of PLGA and PLGA-D particles produced both in this study and previously in the O'Toole lab. Submicrometer particles had a more negative zeta potential which is considered to be less toxic to cells due to the cationic charge cells

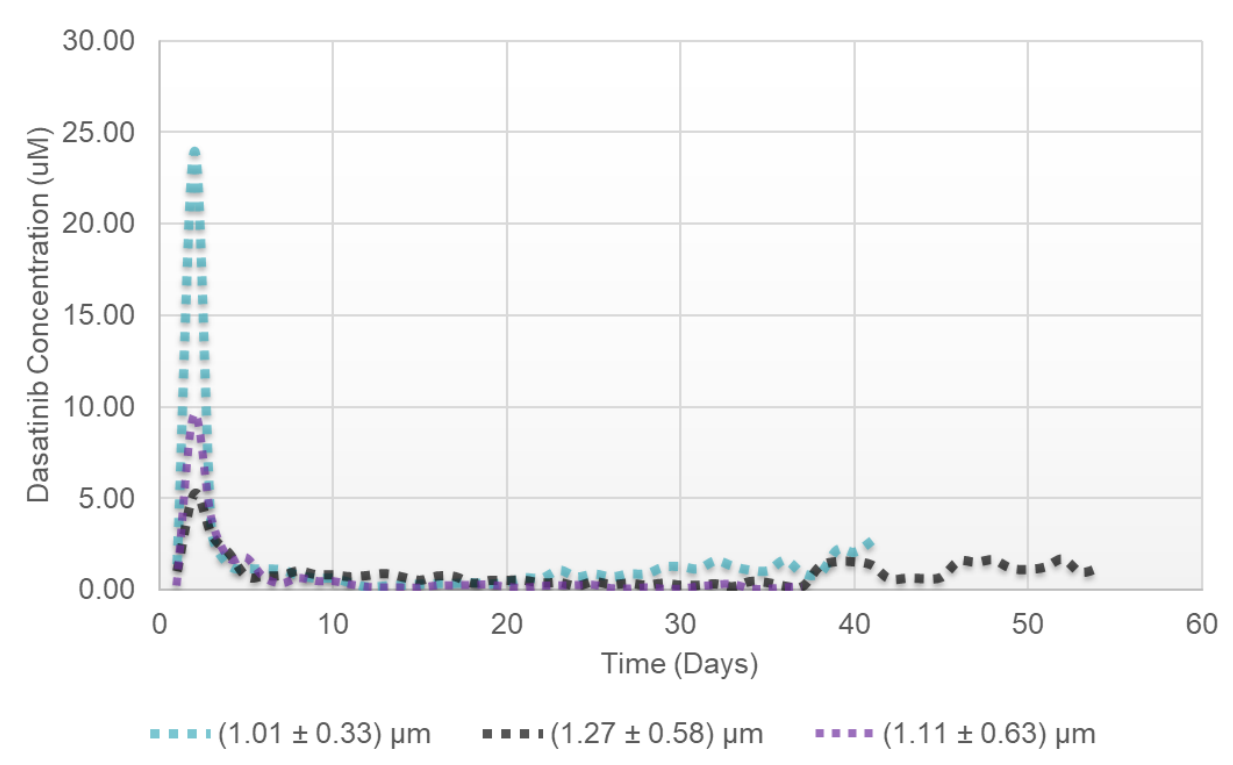

Figure 13. Submicrometer particle controlled release have. $^{71}$ Shao, et. al. found that polymeric nanoparticles with a more negative zeta potential displayed less cytotoxicity than polymeric nanoparticles with a positive zeta potential. ${ }^{72}$ Nanoparticles (NP) with a negative zeta potential were found to cause less damage to cells due to their reduced interaction with the cell membrane, and to undergo phagocytosis easier than their positively charged counterparts. Negatively charged NPs were found to have weak interactions with 
lysosomes and the protein coronas that form around them due to the coronas also being negatively charged.

Positively charged NPs were shown by Shao, et. al. to disrupt the formation of lysosomal membranes and alter biological processes. A controlled release study was performed on all three sets of PLGA-D particles and the results are shown in Figure 13.

The particles released detectable amounts of dasatinib out to 14 days. Unlike the larger particles produced earlier in the study, the submicrometer particles all showed the same drug release profile. The submicrometer particles had a rapid initial release of the drug with $60 \%$ of the dasatinib in the particles being released by the second day of the study. The submicrometer particles released $94 \%$ of their dasatinib concentration within the first week of the experiment and followed the Korsmeyer-Peppas model of drug release mechanisms with Fickian Diffusion. The particle release matching to the Korsmeyer-Peppas model can be seen in the appendix.

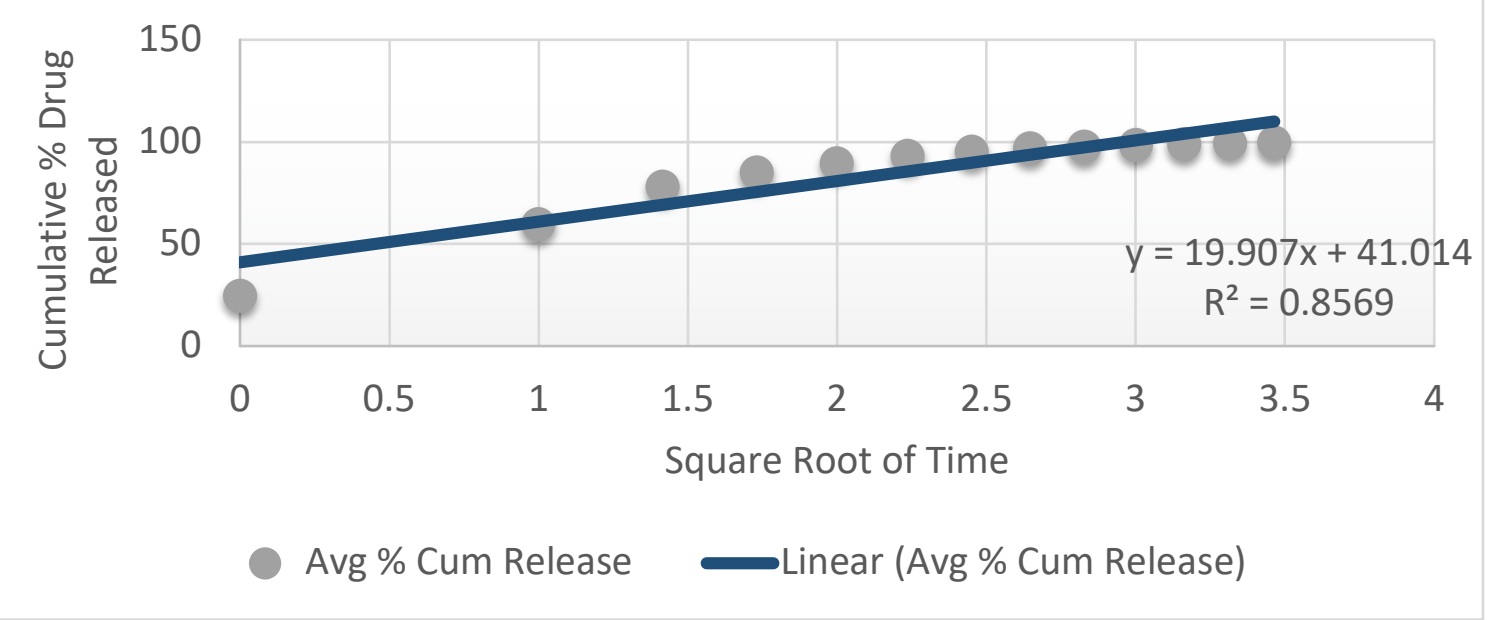

Figure 14. Submicrometer particle controlled release kinetics 
As can be seen from the graphs of the particle release kinetics all three sets of submicrometer particles fit the same release profile whereas the larger particles produced previously had different release profiles. Two additional sets of PLGA-D particles were produced with the same parameters.

The two additional sets of particles that were produced were both under a micrometer in size with sizes of: $0.97 \pm 0.43 \mu \mathrm{m}$ and $0.89 \pm 0.57 \mu \mathrm{m}$, although their drug release kinetics were not determined. The large standard deviations are due to fluctuations in internal pressure of the spray dryer in the inert loop system which is a hallmark characteristic of the spray drying manufacturing method.

\section{CONCLUSIONS AND RECOMMENDATIONS}

Through use of a Taguchi statistical design, it has been shown that PLGA and PLGA dasatinib particles smaller than one micrometer can be produced. These particles displayed a spherical morphology with axial ratio measurements close to one. PLGA-D particle size and morphology effects the immunological reaction by the body and the cellular uptake of the particles. The smaller particle size and spherical morphology increases cellular uptake and reduce immune response.

When loaded with dasatinib, all the submicrometer particles exhibited uniform release kinetics and conformed to the Korsmeyer-Peppas release profile. The particles showed rapid release of dasatinib with sustained dasatinib release up to 14 days. When compared to larger PLGA and PLGA dasatinib particles produced previously in the lab, the smaller particles exhibited greater stability as measured through zeta potential. More negative zeta potential values have been found to be less cytotoxic. 
Further study could involve cellular contraction assays to observe the particles effectiveness at preventing the contracture of retinal pigment epithelium. Additional work that could be done is injecting optimized particles into animal models to observe how they behave in vivo. A recommended animal study would be injecting the PLGA-D particles into porcine models with induced PVR. 
Appendix:

\section{Taguchi matrix PLGA SEM images}

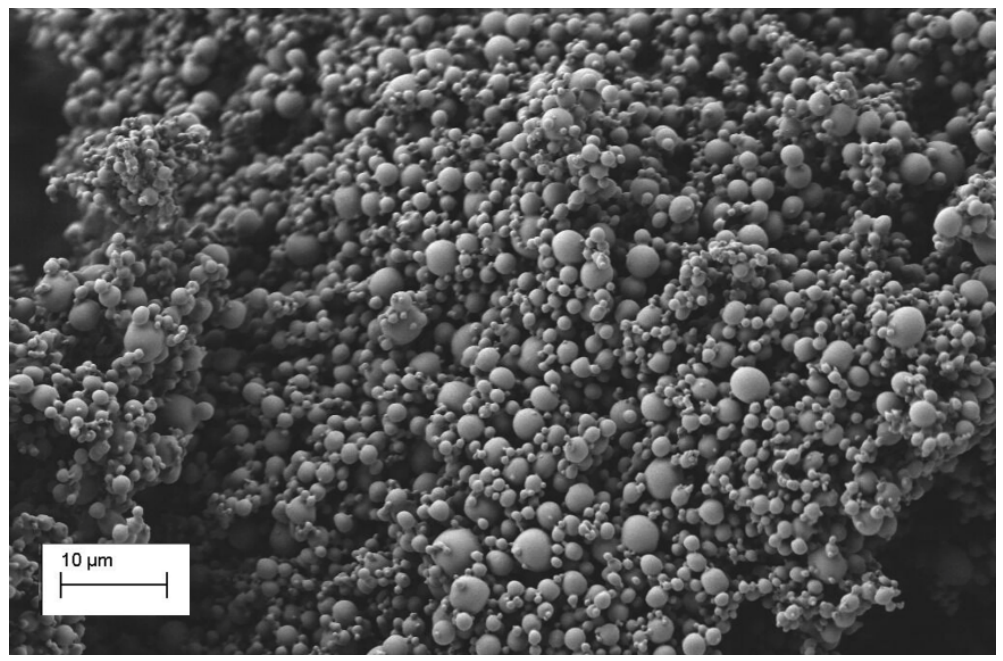

Figure A1. SEM image of Taguchi Trial 1

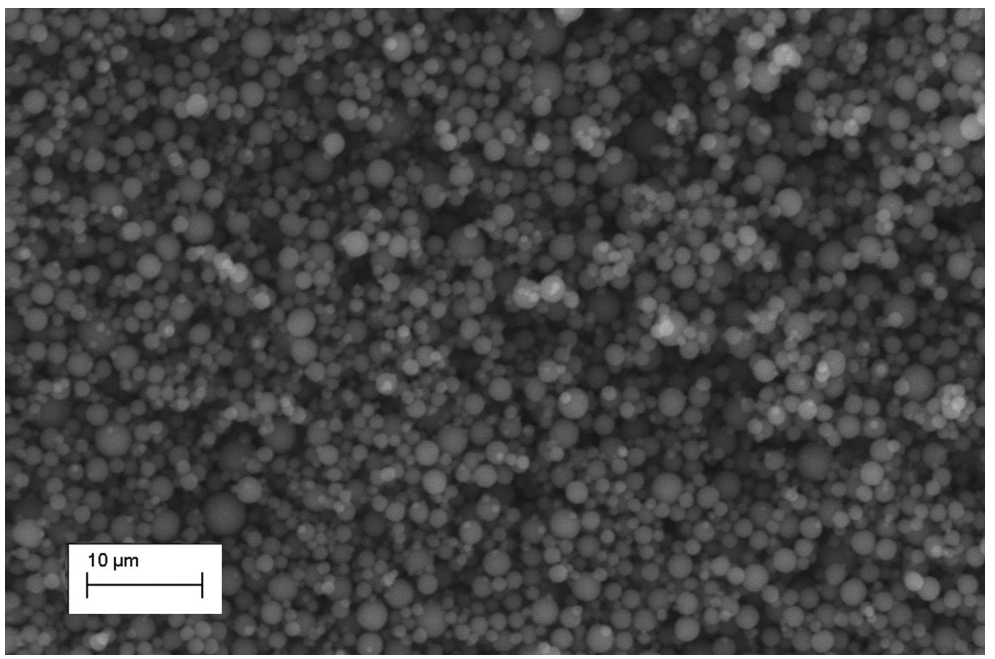

Figure A2. SEM image of Taguchi Trial 2 


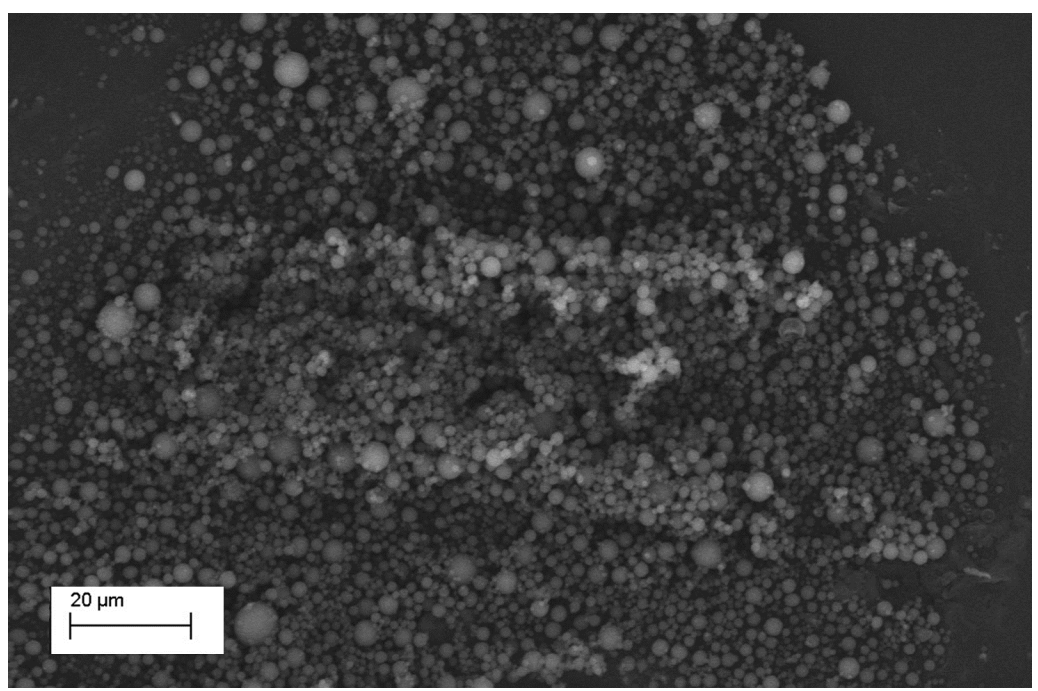

Figure A3. SEM image of Taguchi Trial 3

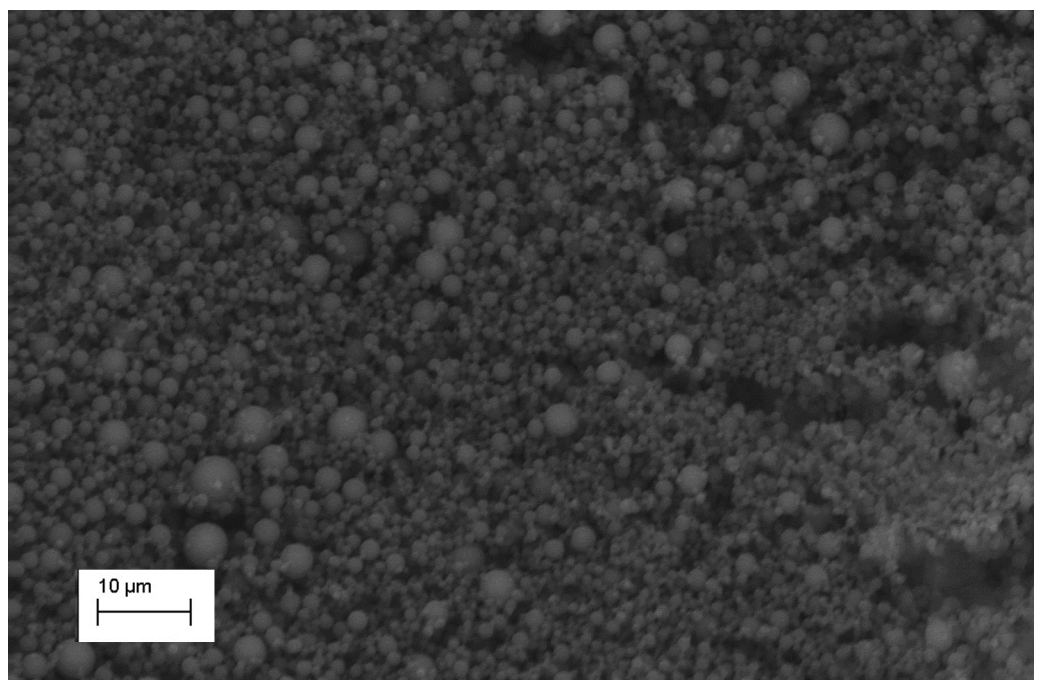

Figure A4. SEM image of Taguchi Trial 4 


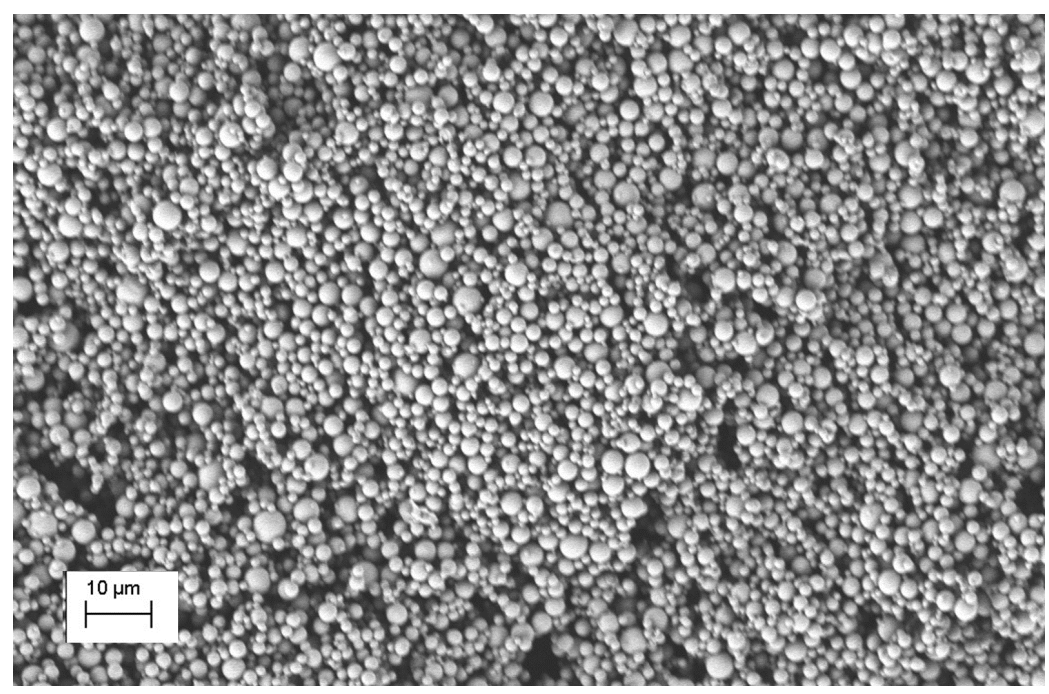

Figure A5. SEM image of Taguchi Trial 5

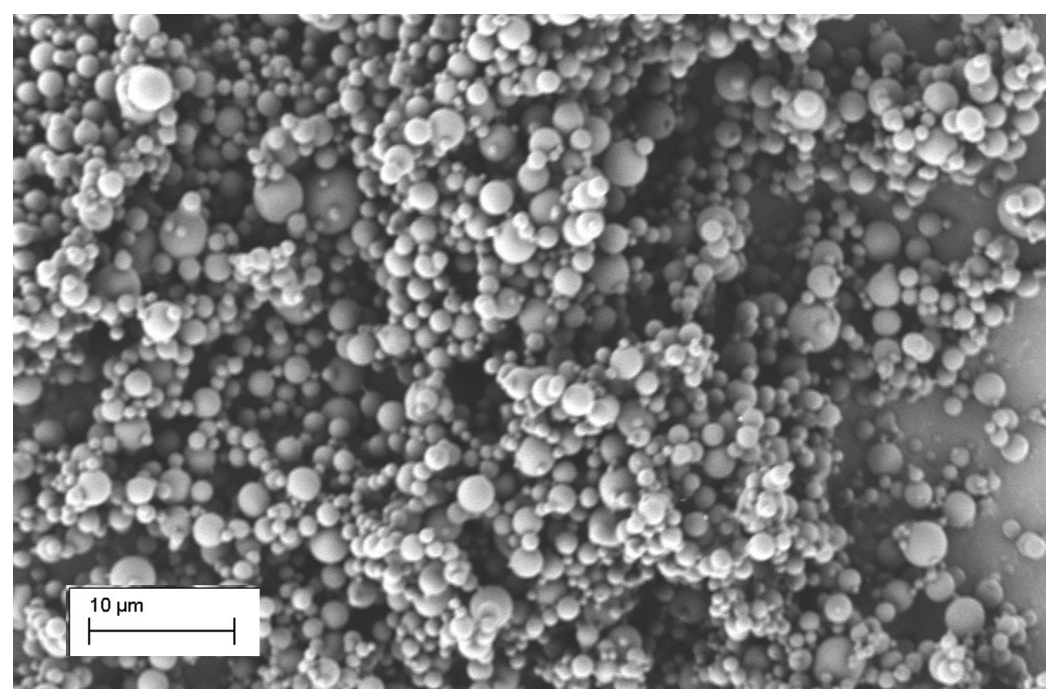

Figure A6. SEM image of Taguchi Trial 6 


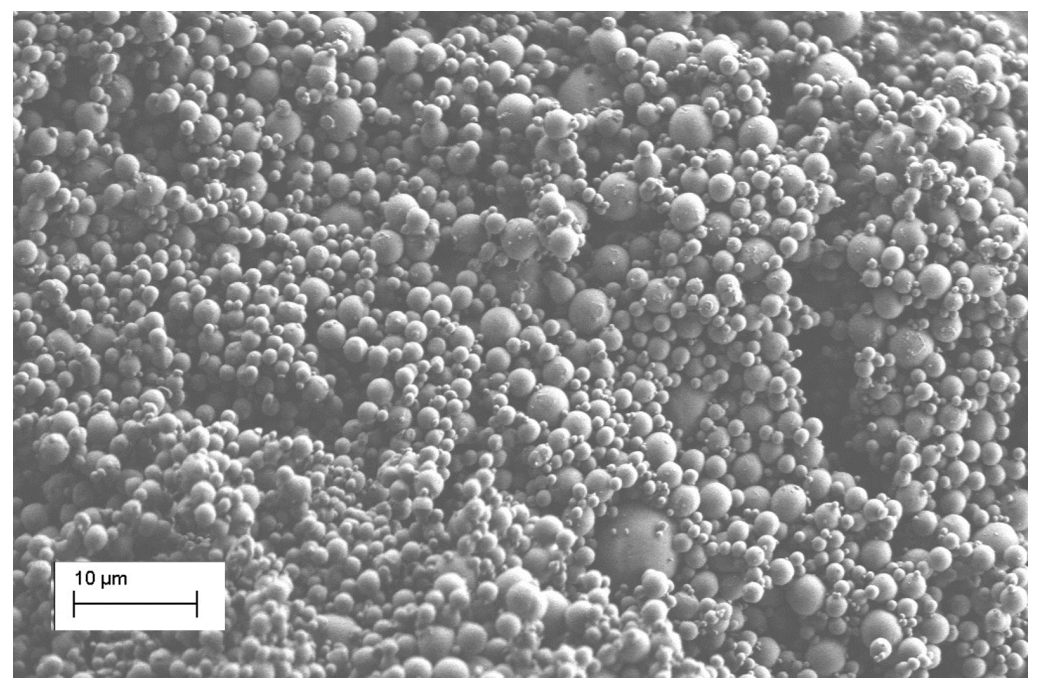

Figure A7. SEM image of Taguchi Trial 7

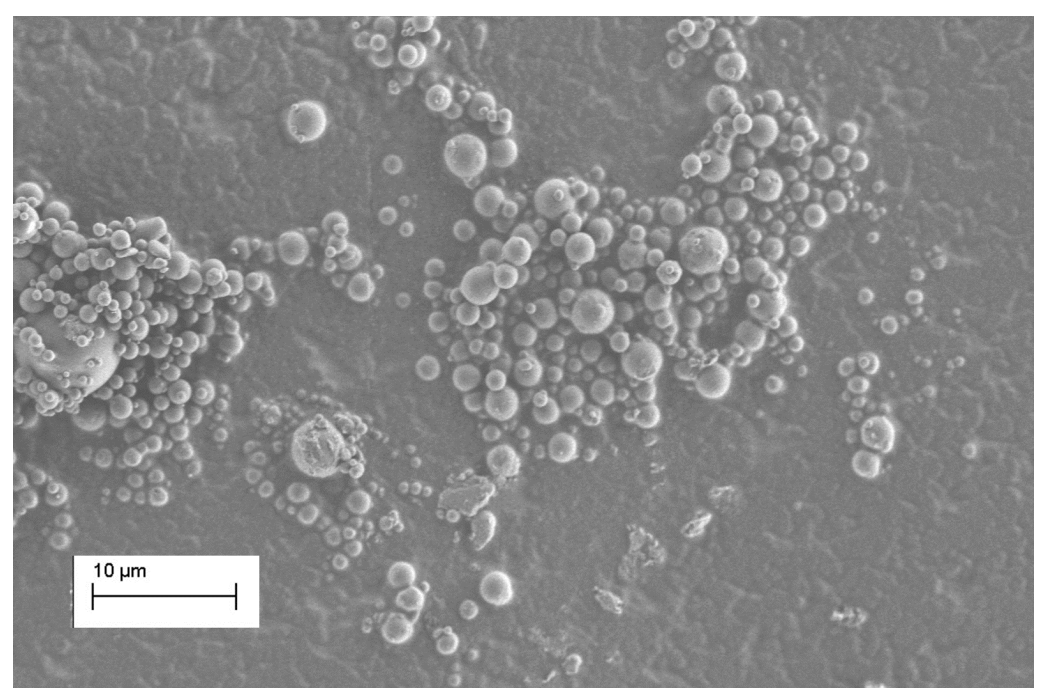

Figure A8. SEM image of Taguchi Trial 8 


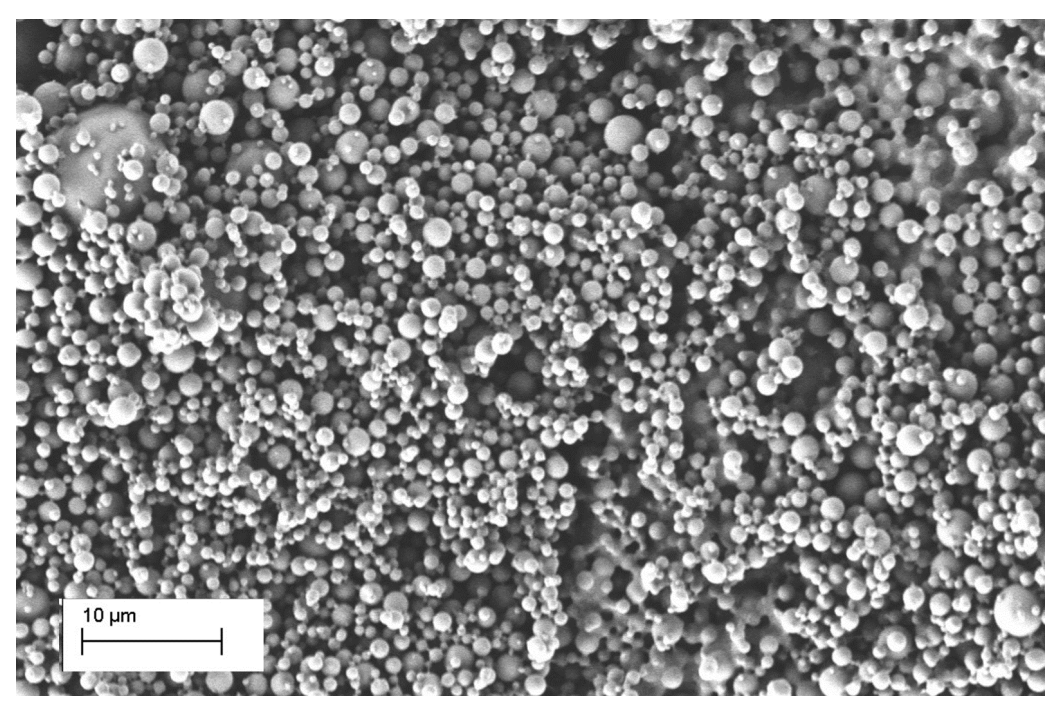

Figure A9. SEM image of Taguchi Trial 9

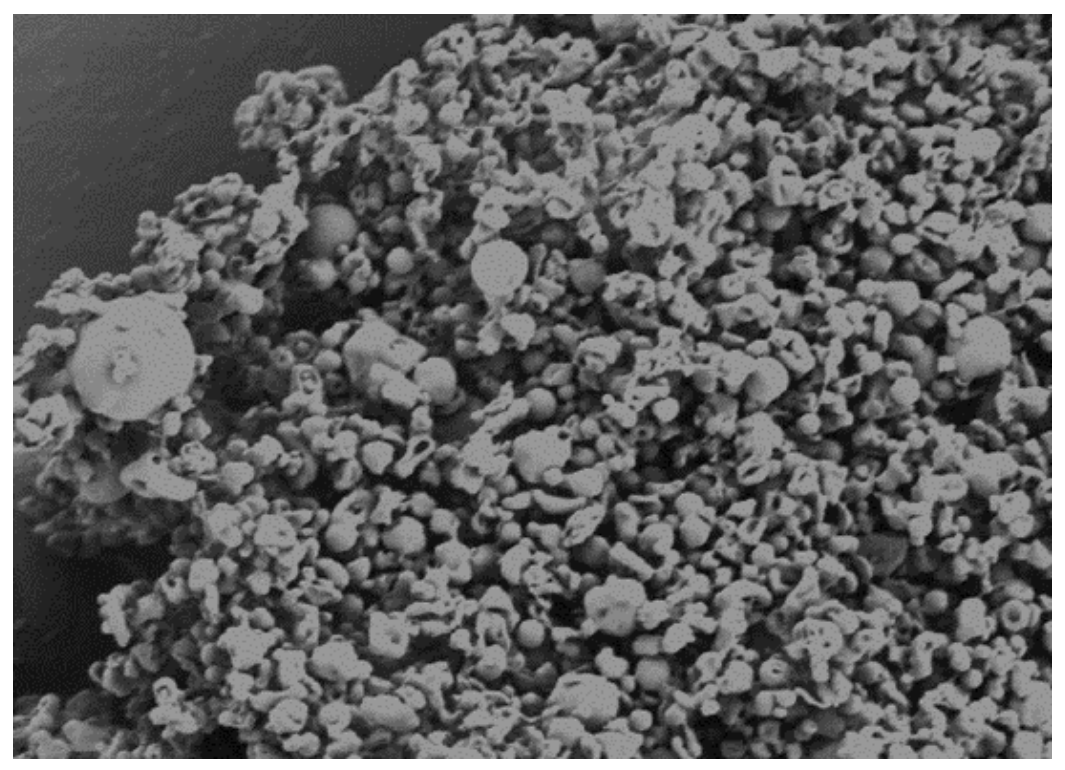

Figure A10. SEM image of $0.25 \%$ PLGA $w / v \%$ particles 


\section{$\underline{\text { Submicrometer Particle Release Kinetics }}$}

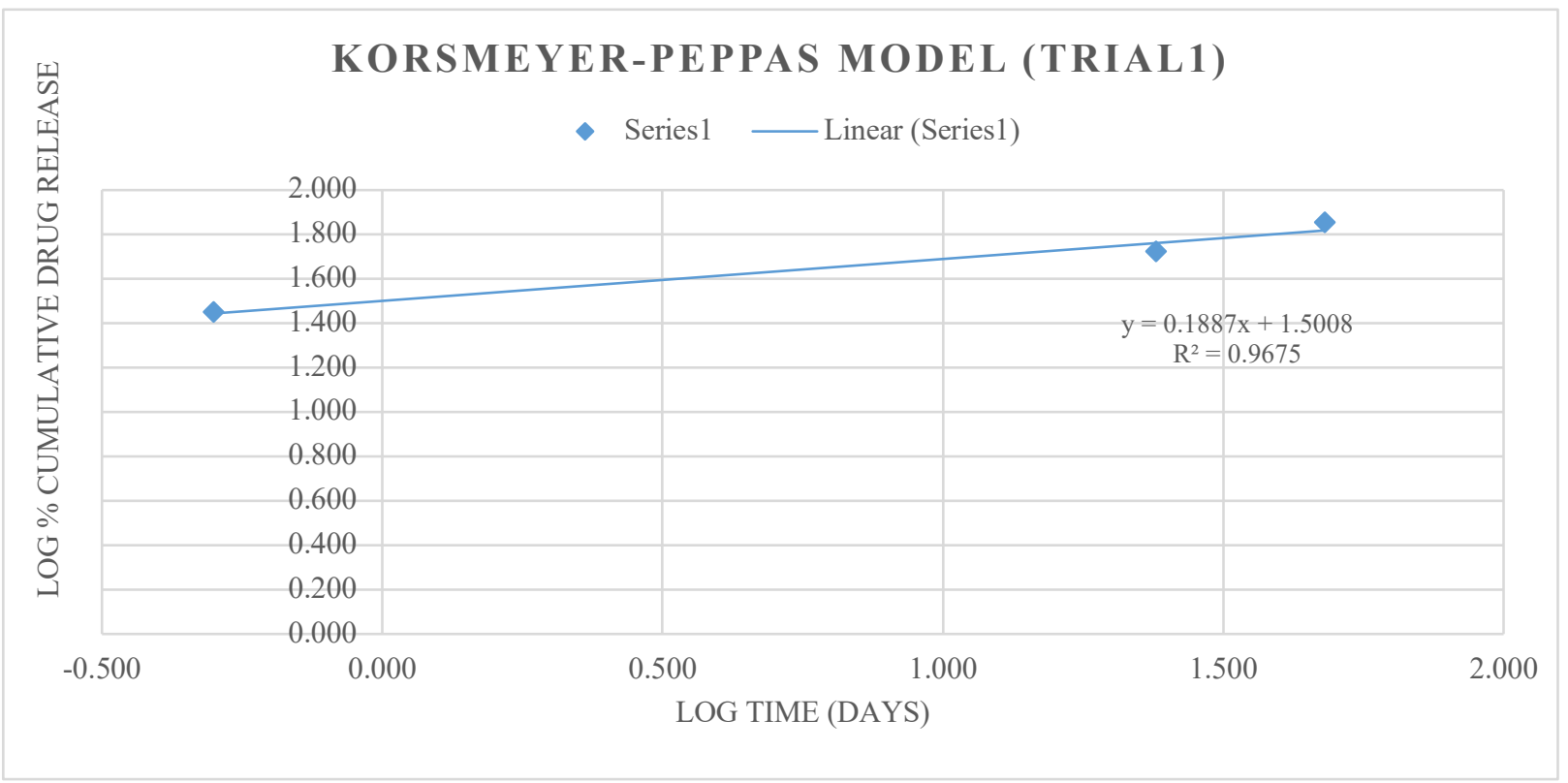

Figure A10. Trial 1 PLGA-D Particle Release Mechanisms

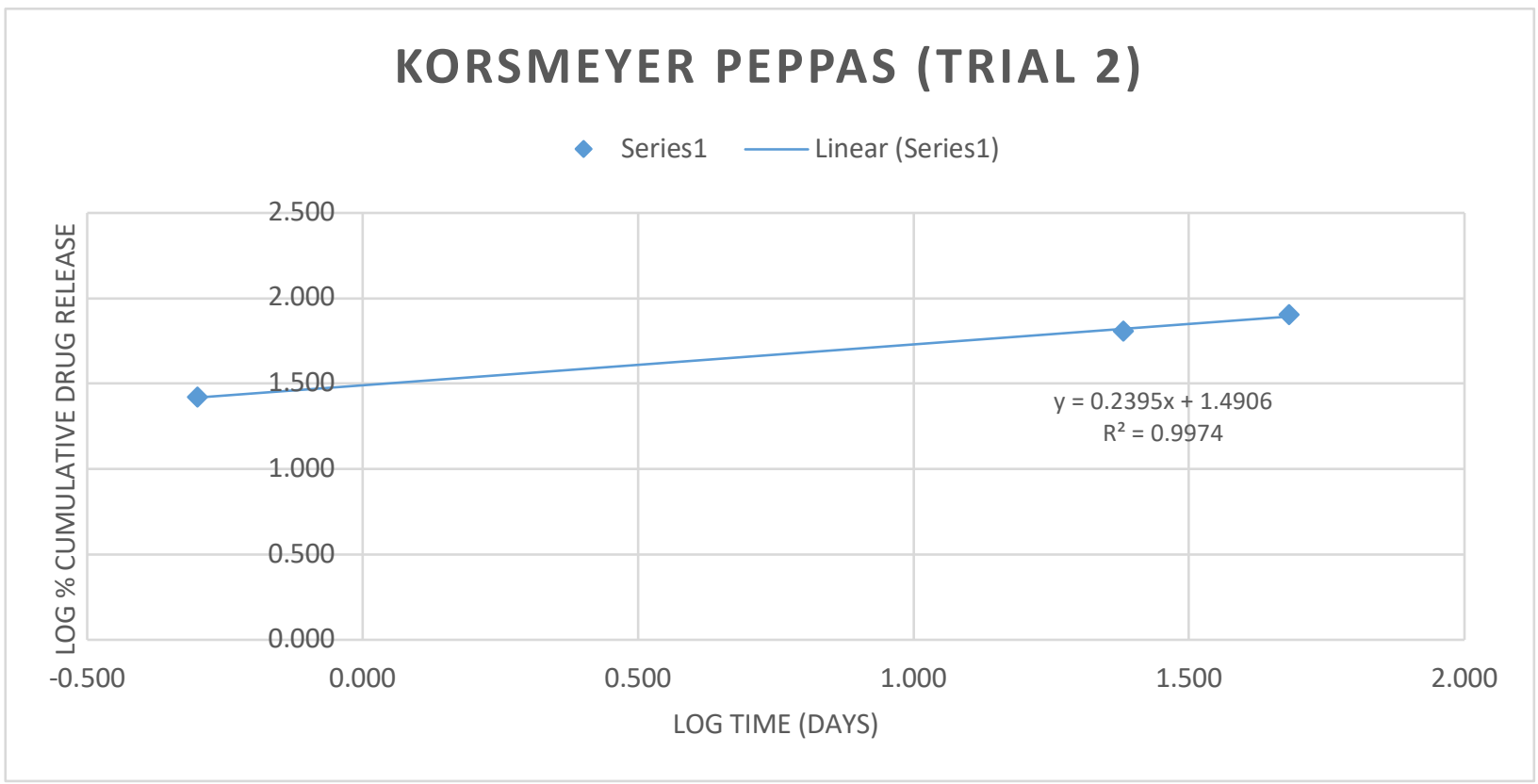

Figure A11. Trial 2 PLGA-D Particle Release Mechanisms 


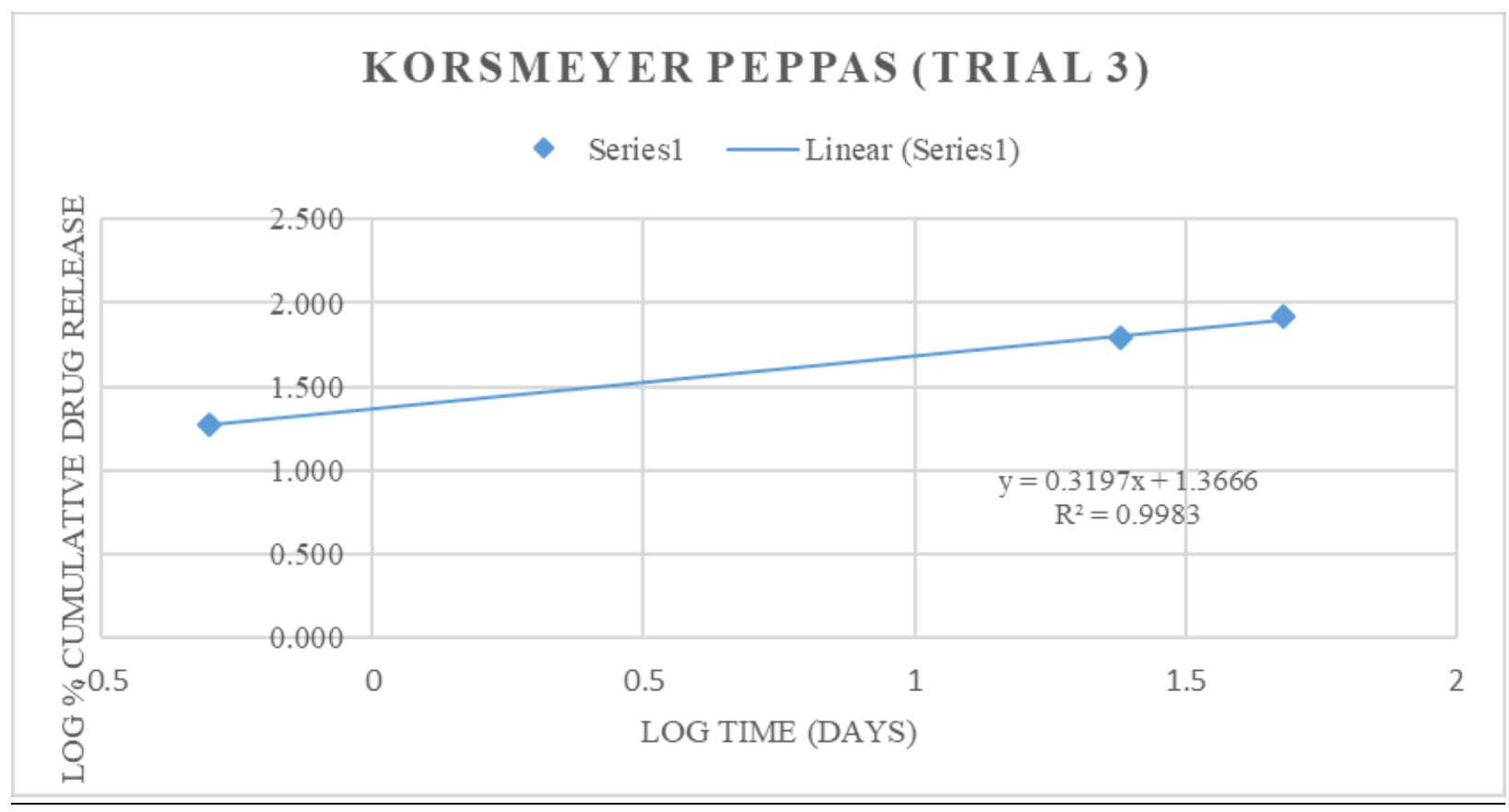

Figure A12. Trial 3 PLGA-D Particle Release Mechanisms

Zeta Potential of PLGA and PLGA-D particles

PLGA-DASATINIB $(\mu \mathrm{M})$

$0.76 \pm 0.32$

$0.73 \pm 0.35$

$0.64 \pm 0.28$

$1.27 \pm 0.58$

$1.11 \pm 0.63$

$1.01 \pm 0.33$
ZETA POTENTIAL (MV)

$-17.32 \pm 4.81$

$-20.69 \pm 3.27$

$-29.93 \pm 2.11$

$-3.95 \pm 6.00$

$5.99 \pm 12.74$

$-1.72 \pm 2.60$

Table A1. Zeta potential measurements of PLGA dasatinib particles

PLGA $(\mu \mathrm{M})$

$0.83 \pm 0.37$

$0.73 \pm 0.40$

$0.62 \pm 0.20$

$1.20 \pm 0.61$

$1.63 \pm 1.56$

$1.11 \pm 0.28$
ZETA POTENTIAL (MV)

$-10.02 \pm 1.38$

$-38.39 \pm 3.55$

$-48.2 \pm 1.43$

$24.42 \pm 13.4$

$-16.95 \pm 17.03$

$-2.3 \pm 11.09$

Table A2. Zeta potential measurements of PLGA particles 


\section{References:}

1. Khurana, A. K., Khurana, A. K., \& Khurana, B. (2015). Comprehensive ophthalmology(Vol. 4). New Delhi: Jaypee, The Health Sciences Publisher.

2. Mccaa, C. S. (1982). The eye and visual nervous system: anatomy, physiology and toxicology. Environmental Health Perspectives, 44, 1-8. doi:10.1289/ehp. 82441

3. Navarro, R. (2009). The Optical Design of the Human Eye: a Critical Review. Journal of Optometry,2(1), 3-18. doi:10.3921/joptom.2009.3

4. Willoughby, C. E., Ponzin, D., Ferrari, S., Lobo, A., Landau, K., \& Omidi, Y. (2010). Anatomy and physiology of the human eye: effects of mucopolysaccharidoses disease on structure and function - a review. Clinical \& Experimental Ophthalmology,38(1), 2-11. doi:10.1111/j.1442-9071.2010.02363.x

5. Cataract Surgery | Online Books | Dr. Robert Maloney. (n.d.). Retrieved March 28, 2018, from https://www.maloneyvision.com/patient-education/onlinebooks/cataract-book/the-human-eye/anatomy-of-the-eye.php

6. Simó, R., Villarroel, M., Corraliza, L., Hernández, C., \& Garcia-Ramírez, M. (2010). The Retinal Pigment Epithelium: Something More than a Constituent of the Blood-Retinal Barrier-Implications for the Pathogenesis of Diabetic Retinopathy. Journal of Biomedicine and Biotechnology,2010, 1-15. doi:10.1155/2010/190724

7. Kolb H. Simple Anatomy of the Retina. 2005 May 1 [Updated 2012 Jan 31]. In: Kolb H, Fernandez E, Nelson R, editors. Webvision: The Organization of the Retina and Visual System [Internet]. Salt Lake City (UT): University of Utah 
Health Sciences Center; 1995-. Available from:

https://www.ncbi.nlm.nih.gov/books/NBK11533/

8. Hall, J. E., \& Guyton, A. C. (2016). Guyton and Hall textbook of medical physiology. Philadelphia, PA: Elsevier.

9. Strauss, O. (2005). The Retinal Pigment Epithelium in Visual Function. Physiological Reviews,85(3), 845-881.

doi:10.1152/physrev.00021.2004

10. Pastor, J. C., Rojas, J., Pastor-Idoate, S., Lauro, S. D., Gonzalez-Buendia, L., \& Delgado-Tirado, S. (2016). Proliferative vitreoretinopathy: A new concept of disease pathogenesis and practical consequences. Progress in Retinal and Eye Research,51, 125-155. doi:10.1016/j.preteyeres.2015.07.005

11. Lo, A. C., Woo, T. T., Wong, R. L., \& Wong, D. (2011). Apoptosis and Other Cell Death Mechanisms after Retinal Detachment: Implications for Photoreceptor Rescue. Ophthalmologica,226(S1), 10-17. doi:10.1159/000328206

12. Khan, M. A., Brady, C. J., \& Kaiser, R. S. (2015). Clinical Management Of Proliferative Vitreoretinopathy. Retina,35(2), 165-175. doi:10.1097/iae.0000000000000447

13. Sadaka, A., Sisk, R., Osher, J., Toygar, O., Duncan, M., \& Riemann, C. (2016). Intravitreal methotrexate infusion for proliferative vitreoretinopathy. Clinical Ophthalmology,Volume 10, 1811-1817. doi:10.2147/opth.s111893

14. Ho, P. C., \& Mcmeel, J. W. (1985). Retinal detachment with proliferative vitreoretinopathy: surgical results with scleral buckling, closed vitrectomy, and 
intravitreous air injection. British Journal of Ophthalmology,69(8), 584-587. doi:10.1136/bjo.69.8.584

15. Christopher J. Brady, MD, Baltimore, and Richard S. Kaiser, MD, Philadelphia. (2015, October 05). PVR: An Update on Prevention \& Management. Retrieved December 12, 2017, from https://www.reviewofophthalmology.com/article/pvran-update-on-prevention--management

16. Garweg, J. G., Tappeiner, C., \& Halberstadt, M. (2013). Pathophysiology of Proliferative Vitreoretinopathy in Retinal Detachment. Survey of Ophthalmology,58(4), 321-329. doi:10.1016/j.survophthal.2012.12.004

17. Eastlake, K., Banerjee, P. J., Angbohang, A., Charteris, D. G., Khaw, P. T., \& Limb, G. A. (2015). Müller glia as an important source of cytokines and inflammatory factors present in the gliotic retina during proliferative vitreoretinopathy. Glia,64(4), 495-506. doi:10.1002/glia.22942

18. Sparrrow, J. R., Hicks, D., \& Hamel, C. P. (2010). The Retinal Pigment Epithelium in Health and Disease. Current Molecular Medicine,10(9), 802-823. doi:10.2174/156652410793937813

19. Li, Z., Sun, L., Zhang, Y., Dove, A. P., O’Reilly, R. K., \& Chen, G. (2016). Shape Effect of Glyco-Nanoparticles on Macrophage Cellular Uptake and Immune Response. ACS Macro Letters,5(9), 1059-1064.

doi:10.1021/acsmacrolett.6b00419

20. Chen, Z., Shao, Y., \& Li, X. (2015). The roles of signaling pathways in epithelialto-mesenchymal transition of PVR. Molecular Vision, 21, 706-710. 
21. Yang, S., Li, H., Li, M., \& Wang, F. (2015). Mechanisms of Epithelial Mesenchymal Transition in Proliferative Vitreoretinopathy. Discovery Medicine,207-217.

22. Andrews, A., Balciunaite, E., Leong, F., Tallquist, M., Soriano, P., Refojo, M., \& Kazaluskas, A. (1999). Platelet-derived growth factor plays a key role in proliferative vitreoretinopathy. Investigative Opthalmological Visual Science,2683-2689.

23. Si, Y., Wang, J., Guan, J., Han, Q., \& Hui, Y. (2013). Platelet-Derived Growth Factor Induced Alpha-Smooth Muscle Actin Expression by Human Retinal Pigment Epithelium Cell. Journal of Ocular Pharmacology and Therapeutics,29(3), 310-318. doi:10.1089/jop.2012.0137

24. Lei, H., Rhéaume, M., Velez, G., Mukai, S., \& Kazlauskas, A. (2011). Expression of PDGFR $\alpha$ Is a Determinant of the PVR Potential of ARPE19 Cells. Investigative Opthalmology \& Visual Science,52(9), 5016. doi:10.1167/iovs.11-7442

25. Moysidis, S. N., Thanos, A., \& Vavvas, D. G. (2012). Mechanisms of Inflammation in Proliferative Vitreoretinopathy: From Bench to Bedside. Mediators of Inflammation,2012, 1-11. doi:10.1155/2012/815937

26. Lindauer, M., \& Hochhause, A. (2010). Dasatinib. Recent Results Cancer Research ,83-102. doi:10.1007/978-3-642-01222-8_7

27. Mendes, T. S., Gomes, A. M., Rocha, B. S., Junior, H. V., \& Abujamra, S. (2015). Evaluation of retinectomy in the treatment of severe proliferative 
vitreoretinopathy. International Journal of Retina and Vitreous, 1(1). doi:10.1186/s40942-015-0018-3

28. Lauro, S. D., Kadhim, M. R., Charteris, D. G., \& Pastor, J. C. (2016). Classifications for Proliferative Vitreoretinopathy (PVR): An Analysis of Their Use in Publications over the Last 15 Years. Journal of Ophthalmology,2016, 1-6. doi:10.1155/2016/7807596

29. Asaria, R. H., Kon, C. H., Bunce, C., Charteris, D. G., Wong, D., Khaw, P. T., \& Aylward, G. W. (2001). Adjuvant 5-fluorouracil and heparin prevents proliferative vitreoretinopathy. Ophthalmology,108(7), 1179-1183. doi:10.1016/s0161-6420(01)00589-9

30. Cunha-Vaz, J. G. (1997). The blood-ocular barriers: past, present, and future. Documenta Ophthalmologica,93(1-2), 149-157. doi:10.1007/bf02569055

31. Li, Q., Lai, K. L., Chan, P. S., Leung, S. C., Li, H. Y., Fang, Y., . . Lee, T. W. (2016). Micellar delivery of dasatinib for the inhibition of pathologic cellular processes of the retinal pigment epithelium. Colloids and Surfaces B: Biointerfaces, 140, 278-286. doi:10.1016/j.colsurfb.2015.12.053

32. Vandyke, K., Fitter, S., \& Zannettino, A. C. (2011). The tyrosine kinase inhibitor dasatinib (SPRYCEL) inhibits chondrocyte activity and proliferation. Blood Cancer Journal, 1(2). doi:10.1038/bcj.2011.1

33. Kantarjian, H., Shah, N. P., Cortes, J. E., Baccarani, M., Bradley-Garelik, M. B., Zhu, C., \& Hochhaus, A. (2011). Dasatinib or imatinib (IM) in newly diagnosed chronic myeloid leukemia in chronic phase (CML-CP): Two-year follow-up from 
DASISION. Journal of Clinical Oncology,29(15_suppl), 6510-6510.

doi:10.1200/jco.2011.29.15_suppl.6510

34. Umazume, K., Liu, L., Scott, P. A., Castro, J. P., Mcdonald, K., Kaplan, H. J., \& Tamiya, S. (2013). Inhibition of PVR with a Tyrosine Kinase Inhibitor, Dasatinib, in the Swine. Investigative Opthalmology \& Visual Science,54(2), 1150. doi:10.1167/iovs.12-10418

35. Chaplot, Sahil \& D Rupenthal, Ilva. (2014). Dendrimers for gene delivery - A potential approach for ocular therapy? The Journal of pharmacy and pharmacology. 66. 542-56. 10.1111/jphp.12104.

36. Siepmann, Jueregen, et al. Fundamentals and Applications of Controlled Release Drug Delivery. Springer, 2012.

37. Duvvuri, S., Majumdar, S., \& Mitra, A. K. (2003). Drug delivery to the retina: challenges and opportunities. Expert Opinion on Biological Therapy,3(1), 45-56. doi:10.1517/14712598.3.1.45

38. Cunha-Vas, J. (1980). Sites and Functions of the Blood-Retinal Barriers. The Blood-Retinal Barriers, 101-117. doi:10.1007/978-1-4757-4655-6_5

39. Patel, A., Cholkar, K., Agrahari, V., \& Mitra, A. K. (2013). Ocular drug delivery systems: An overview. World Journal of Pharmacology, 2(2), 47-64. http://doi.org/10.5497/wjp.v2.i2.47

40. Dash, S., Narashima Murthy, P., Nath, L., \& Chowdhury, P. (2010). Kinetic Modeling on Drug Release from Controlled Drug Delivery Systems. Acta Poloniae Pharmaceutica - Drug Research ,67(3), 217-223. 
41. Siepmann, J., \& Peppas, N. A. (2011). Higuchi equation: Derivation, applications, use and misuse. International Journal of Pharmaceutics, 418(1), 6-12. doi:10.1016/j.ijpharm.2011.03.051

42. Paul, D. (2011). Elaborations on the Higuchi model for drug delivery. International Journal of Pharmaceutics,418(1), 13-17. doi:10.1016/j.ijpharm.2010.10.037

43. Motwani, S., Chopra, S., Talegaonkar, S., Kohli, K., Ahmad, F., \& Khar, R. (2007). Chitosan-sodium alginate nanoparticles as submicroscopic reservoirs for ocular delivery: Formulation, optimisation and in vitro characterisation. European Journal of Pharmaceutics and Biopharmaceutics. doi:10.1016/j.ejpb.2007.09.009

44. Campos, A. M., Sánchez, A., \& Alonso, M. J. (2001). Chitosan nanoparticles: a new vehicle for the improvement of the delivery of drugs to the ocular surface. Application to schasporin A. International Journal of Pharmaceutics, 224(1-2), 159-168. doi:10.1016/s0378-5173(01)00760-8

45. Aksungur, P., Demirbilek, M., Denkbaş, E. B., Vandervoort, J., Ludwig, A., \& Ünlü, N. (2011). Development and characterization of Cyclosporine A loaded nanoparticles for ocular drug delivery: Cellular toxicity, uptake, and kinetic studies. Journal of Controlled Release, 151(3), 286-294.

doi:10.1016/j.jconrel.2011.01.010

46. Gupta, H., Aqil, M., Khar, R. K., Ali, A., Bhatnagar, A., \& Mittal, G. (2010). Sparfloxacin-loaded PLGA nanoparticles for sustained ocular drug delivery. Nanomedicine: Nanotechnology, Biology and Medicine, 6(2), 324-333. doi:10.1016/j.nano.2009.10.004 
47. Zhou, H., Hao, J., Wang, S., Zheng, Y., \& Zhang, W. (2013). Nanoparticles in the ocular drug delivery . International Journal of Ophthalmology,390-396..

48. Chang, E., Mcclellan, A. J., Farley, W. J., \& Li, D. Q. (2011). Biodegradable PLGA-Based Drug Delivery Systems for Modulating Ocular Surface Disease under Experimental Murine Dry Eye. Journal of Clinical \& Experimental Ophthalmology,02(11). doi:10.4172/2155-9570.1000191

49. Gavini, E., Chetoni, P., Cossu, M., Alvarez, M. G., Saettone, M. F., \& Giunchedi, P. (2004). PLGA microspheres for the ocular delivery of a peptide drug, vancomycin using emulsification/spray-drying as the preparation method: in vitro/in vivo studies. European Journal of Pharmaceutics and Biopharmaceutics, 57(2), 207-212. doi:10.1016/j.ejpb.2003.10.018

50. Abrego, G., Alvarado, H. L., Egea, M. A., Gonzalez-Mira, E., Calpena, A. C., \& Garcia, M. L. (2014). Design of Nanosuspensions and Freeze-Dried PLGA Nanoparticles as a Novel Approach for Ophthalmic Delivery of Pranoprofen. Journal of Pharmaceutical Sciences, 103(10), 3153-3164. doi:10.1002/jps.24101

51. Schafroth, N., Arpagaus, C., Jadhav, U. Y., Makne, S., \& Douroumis, D. (2012). Nano and microparticle engineering of water insoluble drugs using a novel spraydrying process. Colloids and Surfaces B: Biointerfaces,90, 8-15. doi:10.1016/j.colsurfb.2011.09.038

52. Nandiyanto, A. B., \& Okuyama, K. (2011). Progress in developing spray-drying methods for the production of controlled morphology particles: From the 
nanometer to submicrometer size ranges. Advanced Powder Technology,22(1), 119. doi:10.1016/j.apt.2010.09.011

53. Kacker, R. N., Lagergren, E. S., \& Filliben, J. J. (1991). Taguchi’s Orthogonal Arrays Are Classical Designs of Experiments. Journal of Research of the National Institute of Standards and Technology, 96(5), 577-591. http://doi.org/10.6028/jres.096.034

54. Beck-Broichsitter, M., Schweiger, C., Schmehl, T., Gessler, T., Seeger, W., \& Kissel, T. (2012). Characterization of novel spray-dried polymeric particles for controlled pulmonary drug delivery. Journal of Controlled Release, 158(2), 329335. doi:10.1016/j.jconrel.2011.10.030

55. Vehring, R. (2007). Pharmaceutical Particle Engineering via Spray Drying. Pharmaceutical Research,25(5), 999-1022. doi:10.1007/s11095-007$9475-1$

56. Tseng, Y., Linehan, B., Ng, K. J., Smith, D. M., Markert, M., Patel, M., ... Fryer, R. M. (2016). Cardiovascular safety pharmacology studies in dogs enabled for a poorly soluble molecule using spray-dried dispersion: Impact on lead selection. International Journal of Pharmaceutics,512(1), 137-146. doi:10.1016/j.ijpharm.2016.08.028

57. Harsha, S. N., Aldhubiab, B. E., Nair, A. B., Alhaider, I. A., Attimarad, M., Venugopala, K. N., ... Asif, A. H. (2015). Nanoparticle formulation by Büchi B90 Nano Spray Dryer for oral mucoadhesion. Drug Design, Development and Therapy, 9, 273-282. http://doi.org/10.2147/DDDT.S66654 
58. Lee, S. H., Heng, D., Ng, W. K., Chan, H., \& Tan, R. B. (2011). Nano spray drying: A novel method for preparing protein nanoparticles for protein therapy. International Journal of Pharmaceutics, 403(1-2), 192-200. doi:10.1016/j.ijpharm.2010.10.012

59. Labpinions. (2009, December 17). Büchi's Nano Spray Dryer B-90. Retrieved December 12, 2017, from http://www.labpinions.com/industry-news/buchis-nanospray-dryer-b-90

60. A Design of Experiment Study of Nanoprecipitation and Nano Spray Drying as Processes to Prepare PLGA Nano- and Microparticles with Defined Sizes and Size Distributions, Research Gate , Feb. 2015, www.researchgate.net/figure/Schematic-set-up-of-the-Buechi-Nano-Spray-DryerB-90_fig1_272186597.Nano Spray Dryer ü-90 HP Technical data sheet. (n.d.). Retrieved from http://static1.buchi.com/sites/default/files/technical-data-pdf/B90_Data Sheet en.pdf?d4484c908799b3b23f663162d5b235c5d68bd56a

61. Gu, B., Linehan, B., \& Tseng, Y. (2015). Optimization of the Büchi B-90 spray drying process using central composite design for preparation of solid dispersions. International Journal of Pharmaceutics,491(1-2), 208-217. doi:10.1016/j.ijpharm.2015.06.006

62. Pang, J., Ansari, M., Zaroog, O. S., Ali, M. H., \& Sapuan, S. (2014). Taguchi design optimization of machining parameters on the $\mathrm{CNC}$ end milling process of halloysite nanotube with aluminium reinforced epoxy matrix (HNT/Al/Ep) hybrid composite. HBRC Journal,10(2), 138-144. doi:10.1016/j.hbrcj.2013.09.007 
63. Uppsala Network of Electron Microscopy. (2012, May). Retrieved December 12, 2017, from http://www2.teknik.uu.se/unem/info_on_units_unem.htm

64. Deposition Equipment. (n.d.). Retrieved March 28, 2018, from https://mobile.labx.com/deposition-equipment?page $=10$

65. Rueden, C. T., \& Eliceiri, K. W. (2017). The ImageJ Ecosystem: An Open and Extensible Platform for Biomedical Image Analysis. Microscopy and Microanalysis,23(S1), 226-227. doi:10.1017/s1431927617001817

66. What is the signal-to-noise ratio in a Taguchi design? (n.d.). Retrieved December 12, 2017, from http://support.minitab.com/en-us/minitab/17/topiclibrary/modeling-statistics/doe/taguchi-designs/what-is-the-signal-to-noise-ratio/

67. Documentation, S. (n.d.). Taguchi Methods: Robust Design Experiments - Signalto-Noise (S/N) Ratios. Retrieved December 12, 2017, from http://documentation.statsoft.com/STATISTICAHelp.aspx?path=Experimental\%2 FDoe\%2FOverview\%2FTaguchiMethodsSignaltoNoiseSNRatios

68. O’Toole, M. G., Henderson, R. M., Soucy, P. A., Fasciotto, B. H., Hoblitzell, P. J., Keynton, R. S., . . Gobin, A. S. (2012). Curcumin Encapsulation in Submicrometer Spray-Dried Chitosan/Tween 20

Particles. Biomacromolecules, 13(8), 2309-2314. doi:10.1021/bm300564v

69. Clogston, J. D., \& Patri, A. K. (2010). Zeta Potential Measurement. Methods in Molecular Biology Characterization of Nanoparticles Intended for Drug Delivery,63-70. doi:10.1007/978-1-60327-198-1_6

70. Shao, X., Wei, X., Song, X., Hao, L., Cai, X., Zhang, Z., . . Lin, Y. (2015). Independent effect of polymeric nanoparticle zeta potential/surface charge, 
on their cytotoxicity and affinity to cells. Cell Proliferation,48(4), 465-474.

doi:10.1111/cpr.12192 


\section{CURRICULUM VITAE}

\section{EDUCATION}

MEng in Bioengineering

\section{EMPLOYMENT HISTORY}

\section{Essex Bargain Hunt}

Process Engineer

- Performed and analyzed time studies to improve production

- Improved production by $25 \%$ on one processing line

- Developed standard operating guidelines for processing procedures

- Developed and implemented training for processing supervisors and processors

\section{University of Louisville}

Graduate Research Assistant

- Proficient on the use of a Büchi B-90 Nano Spray dryer

- Cell culture experience

- Level I/II animal training

- Presented at Research Louisville and Biomedical Engineering society

\section{Ceva Logistics}

Process Engineering Intern

- Performed and analyzed time studies to improve manufacturing processes

- Improved average worker productivity by $17 \%$ in one area and $13 \%$ in another area

- Implemented 5S and lean manufacturing tenants to improve productivity and worker morale

- Improved cycle time by 9 seconds per product ( $25 \%$ overall improvement)

- Direct cost savings from implementing process improvements $\$ 150,000$

\section{Boston Scientific}

Manufacturing Engineering Intern

- Designed a uniform system for tracking material usage variance

- Identified and properly escalated a scrap issue saving the line $\$ 1500 /$ month in scrap expenses

- Supported the primary manufacturing engineer on two in sourcing projects

- Learned lean manufacturing procedures and processes through company provided training

\section{Kindred Health Facility}

Certified Nurse Assistant,

- Answered patient questions as well as nurse questions.

- Kept detailed charts and information on patient care and vital signs.

- Assisted patients in all areas of daily life including feeding, bathing, and dressing.

- Learned how to handle difficult situations such as addressing patient and family interactions

- Assisted the elderly and incapacitated through the final li phase of life. 
ACTIVITIES \& HONORS

- Kosair's Women and Children Hospital, volunteer

- Hospice Volunteer Oct 2016 - May 2017

- Kentucky Academy of Science - Graduate Research Oral Presentation $1^{\text {st }}$ Place November 2016

- Paper publication: Investigative Ophthalmology and Visual Science July 2017

- Pending paper publication: Machine Learning Journal December 2016 